This item was submitted to Loughborough's Research Repository by the author.

Items in Figshare are protected by copyright, with all rights reserved, unless otherwise indicated.

\title{
Production of multiple emulsions for drug delivery systems by repeated SPG membrane homogenization: Influence of mean pore size, interfacial tension and continuous phase viscosity
}

\section{PLEASE CITE THE PUBLISHED VERSION}

http://dx.doi.org/10.1016/j.memsci.2006.08.003

\section{PUBLISHER}

(C) Elsevier

\section{VERSION}

AM (Accepted Manuscript)

\section{LICENCE}

CC BY-NC-ND 4.0

\section{REPOSITORY RECORD}

Vladisavljevic, Goran T., Masataka Shimizu, and Tadao Nakashima. 2012. "Production of Multiple Emulsions for Drug Delivery Systems by Repeated SPG Membrane Homogenization: Influence of Mean Pore Size, Interfacial Tension and Continuous Phase Viscosity". figshare. https://hdl.handle.net/2134/10553. 
This item was submitted to Loughborough's Institutional Repository (https://dspace.lboro.ac.uk/) by the author and is made available under the following Creative Commons Licence conditions.

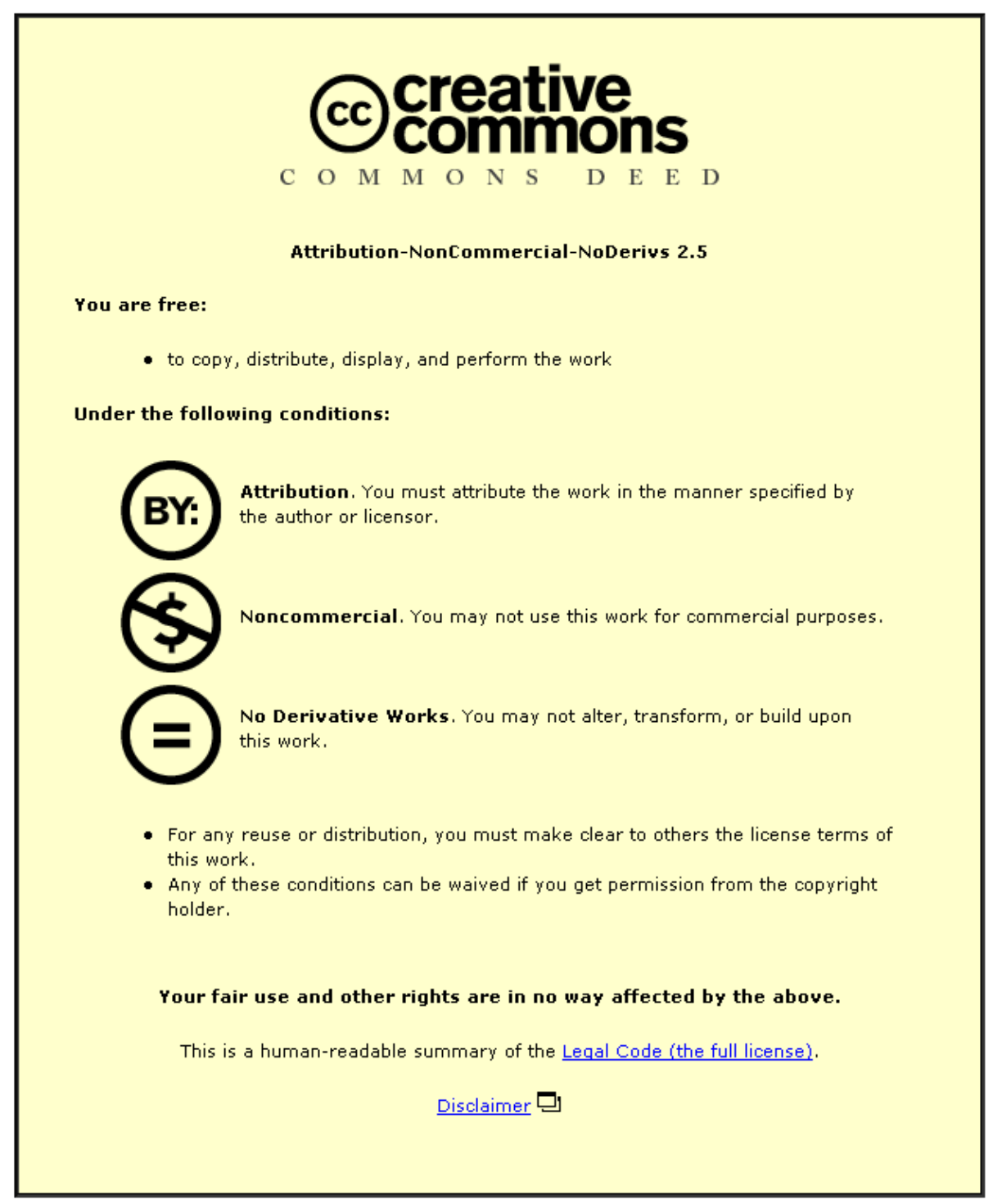

For the full text of this licence, please go to: http://creativecommons.org/licenses/by-nc-nd/2.5/ 


\section{Production of multiple emulsions for drug delivery systems by repeated SPG membrane homogenization: Influence of mean pore size, interfacial tension and continuous phase viscosity}

Goran T. Vladisavljevic ${ }^{\mathrm{a}^{*}}$, Masataka Shimizu ${ }^{\mathrm{b}}$, Tadao Nakashima ${ }^{\mathrm{c}}$

${ }^{a}$ Institute of Food Technology and Biochemistry, Faculty of Agriculture, University of Belgrade, P.O. Box 127, YU-11081 Belgrade-Zemun, Serbia.

bMiyazaki Prefectural Industrial Technology Center, 16500-2 Higashi-Kaminaka, Sadowara, Miyazaki 880-0303, Japan.

'Miyazaki Prefectural Mechanical Technology Center, 39-82 Otake, Nobeoka, Miyazaki 882-0024, Japan.

Abstract

Multiple water-in-oil-in-water (W/O/W) emulsions for drug delivery systems were produced by extruding a coarse W/O/W emulsion 5 times under pressure of 70$150 \mathrm{kPa}$ through Shirasu Porous Glass (SPG) membrane with a mean pore size of 5.4, 7.6, 10.7, 14.8, and $20.3 \mu \mathrm{m}$. The encapsulation efficiency of a marker (CaNa $\left.\mathrm{C}_{2} \mathrm{EDTA}\right)$ determined by Inductively Coupled Plasma (ICP) emission spectrophotometer was 83$85 \%$ in the emulsion products containing 30 vol\% of inner droplets and $30-50$ vol\% of outer drops. The ratio of mean particle size to the mean pore size after five extrusions decreased from 1.25 to 0.68 as the pore size increased from 5.4 to $20.3 \mu \mathrm{m}$ at the wall

*Corresponding author: Tel: +381 112615315 ext. 327; Fax: +381 112199711 e-mail address: gtvladis@afrodita.rcub.bg.ac.yu 
shear stress of continuous phase in the pores of $200 \mathrm{~Pa}$. The mean particle size of the resultant droplets decreased with increasing the continuous phase viscosity and with decreasing the pore size. The ratio of mean particle size to the mean pore size for the same multiple emulsions prepared by direct extrusion of W/O emulsions through SPG membrane into stirring continuous phase was 3.46 and was independent on the pore size. At low continuous phase viscosity, uniform droplets with a span values of 0.28 0.34 were produced at very high transmembrane fluxes exceeding $200 \mathrm{~m}^{3} \mathrm{~m}^{-2} \mathrm{~h}^{-1}$.

Keywords: Membrane emulsification; Shirasu Porous Glass membrane; Multiple emulsion; Premix membrane emulsification; Drug delivery system.

\section{Introduction}

A multiple (double or complex) emulsion is an emulsion in an emulsion [1]. A W/O/W emulsion consists of water droplets dispersed within larger oil droplets, which are themselves dispersed in an aqueous continuous phase. In an $\mathrm{O} / \mathrm{W} / \mathrm{O}$ emulsion, larger water droplets enclosing smaller oil droplets are dispersed in a continuous oil phase. Multiple emulsions may find many potential applications in various fields such as chemistry [2], pharmaceutics [3], cosmetics [4], and food [5]. These emulsions have been investigated as controlled-release drug delivery systems (DDS) [3], as 'emulsion liquid membranes' for simultaneous liquid extraction and stripping of metals [6], organic acids [7] and antibiotics [8], as microcapsules for the protection and controlled release of functional food ingredients [9], for the formulation of reduced-calorie food emulsions [10], etc. Other applications include the use of multiple emulsions as intermediate products to the preparation of inorganic particles [11], lipid nanoparticles 
[12], polymeric microspheres [13-14], biodegradable microspheres [15], gel microbeads [16], and vesicles such as polymerosomes [17].

Multiple emulsions are usually formed by a two-step emulsification process using conventional rotor-stator or high pressure valve homogenizers [1]. The primary W/O or $\mathrm{O} / \mathrm{W}$ emulsion is prepared under high-shear conditions to obtain small inner droplets, while the secondary emulsification step is carried out with less shear to avoid rupture of the liquid membrane between the innermost and outermost phase. However, the second step often results in highly polydisperse outer drops (if homogenizing conditions are too mild) or in a small encapsulation efficiency (if homogenization is too intensive).

Multiple emulsions can alternatively be produced by forcing a primary emulsion through a microporous membrane [18-21] or microfabricated channel arrays [16, 22-23] into a continuous phase liquid. This results in much less shear than in conventional emulsification processes so that the droplets are intact and both a high entrapment efficiency and monodispersity can be achieved [24, 14]. In addition, the mean size of the outer drops can precisely be adjusted over a wide range by changing the membrane pore size or the geometry of microchannel arrays. A higher degree of control over the resultant double emulsions can be achieved using microfluidic devices, but at very small production scales. The two most commonly used microfluidic geometries are the Tjunction [25] and flow focusing device (FFD) [26]. Okushima et al. [27] generated monodisperse double emulsions with $100 \%$ entrapment efficiency and a controlled number of droplets encapsulated in each larger drop using two T-junctions in series with alternating wettabilities. Uniformly sized double and triple emulsions were produced in a single step by hydrodynamic focusing of coaxial liquid streams in microfluidic flow focusing devices of different design [17, 28, 29]. 
'Direct membrane emulsification' has been extensively investigated over the past 15 years for the generation of uniformly sized emulsion droplets at laboratory scales [30-35]. However, this process suffers from low productivity (a dispersed phase flux is typically in the range from 5 to $100 \mathrm{Lm}^{-2} \mathrm{~h}^{-1}$ ), which is associated with the necessity to prevent the continuous outflow of dispersed phase through the pores [36] or the steric hindrance between the droplets on the membrane surface [37, 32]. Suzuki et al. [38-40] implemented premix membrane emulsification, in which a coarsely emulsified mixture rather than a pure liquid is forced through the membrane to achieve a geometrically mediated controlled breakup of drops inside the pores. The major advantages of this approach are that emulsions with higher droplet concentrations (30-60 vol\%) can more easily be produced and higher transmembrane fluxes can be achieved (generally above 1 $\mathrm{m}^{3} \mathrm{~m}^{-2} \mathrm{~h}^{-1}$ ), but at the expense of higher degree of droplet polydispersity. The droplet monodispersity can be improved by extruding emulsion through the membrane several times [41-46], which is a technique originally developed for the production of lipid vesicles using track-etch polycarbonate membranes [47]. Monodisperse emulsions are more favorable in both industrial applications and fundamental studies. Appearance, rheology, stability against Oswald ripening and creaming, drug-release properties, and the suitability of multiple emulsions as precursors to the production of structured solids are strongly influenced by their particle size distribution [48].

Our previous study [44] was focused on the effect of transmembrane pressure, number of passes through the membrane and dispersed phase content on the particle size distribution and transmembrane flux in repeated SPG membrane homogenization. The mean pore size was $10.7 \mu \mathrm{m}$ and the continuous phase viscosity was fixed at 126 $\mathrm{mPa} \cdot \mathrm{s}$ to decrease the creaming rate of crude feed emulsions. We produced $\mathrm{W} / \mathrm{O} / \mathrm{W}$ 
emulsions containing 1-60 vol\% of outer drops with a span of the size distribution of about 0.28 at the transmembrane fluxes of up to $37 \mathrm{~m}^{3} \mathrm{~m}^{-2} \mathrm{~h}^{-1}$. The aim of this work is to investigate the effect of the mean pore size of SPG membrane, the interfacial tension at oil-water interface, the continuous phase viscosity, and the content of inner droplets on the particle size distribution and transmembrane flux in repeated SPG homogenization. We also measured the entrapment efficiency of a hydrophilic marker substance, because high transmembrane fluxes in addition to repeated passes through the membrane could adversely affect the yield of inner droplets.

\section{Experimental}

\subsection{Materials}

The oil phase in $\mathrm{W}_{1} / \mathrm{O} / \mathrm{W}_{2}$ emulsions was $5 \mathrm{wt} \%$ polyglycerol polyricinoleate (PGPR) dissolved in soybean oil with a density of $920 \mathrm{~kg} / \mathrm{m}^{3}$ at $298 \mathrm{~K}$. The inner aqueous phase $\left(\mathrm{W}_{1}\right)$ contained $5 \mathrm{wt} \%$ glucose as an osmotic additive and $2 \mathrm{wt} \% \mathrm{CaNa}_{2}-$ EDTA (calcium disodium ethylendiaminetetraacetate) as a marker substance for the determination of encapsulation efficiency. The outer aqueous phase $\left(\mathrm{W}_{2}\right)$ contained 0.5 wt\% Tween 80 (polyoxyethylene (20) sorbitan monooleate) as an emulsifier, 5 wt\% glucose, and $1 \mathrm{wt} \%$ sodium alginate as a thickening agent. In some experiments sodium alginate was not added to investigate the effect of continuous phase viscosity on droplet breakup behavior. PGPR was purchased from Sakamoto Yakuhin Kogyo (Osaka, Japan), $\mathrm{CaNa}_{2}$-EDTA was obtained from Dojindo and other chemicals were supplied from Wako Pure Chemical Industries (Osaka, Japan). The viscosity of continuous phase containing 1 wt\% sodium alginate was 126 and $146 \mathrm{mPa} \cdot \mathrm{s}$ at 303 and $297 \mathrm{~K}$, respectively, measured by a digital rotational viscometer (DVL-B, Tokimec, No. 5 
rotor). The role of glucose was to increase the osmotic pressure in both aqueous phases to $0.78 \mathrm{MPa}$, which is the osmotic pressure of blood and other body liquids. The formulation of the product emulsions and the range of mean particle sizes obtained are listed in Tab. 1.

\subsection{Membranes and membrane module}

Shirasu Porous Glass (SPG) membrane tubes $(8.5 \mathrm{~mm}$ inner diameter $\times 0.8 \mathrm{~mm}$ wall thickness), supplied from SPG Technology (Sadowara, Japan) were used in all experiments. The mean pore size $d_{p}$ of the membrane was $20.3,14.7,10.7,7.6$, and 5.4 $\mu \mathrm{m}$, the wall porosity $\varepsilon$ was $50-58 \%$, and the mean pore tortuosity $\xi$ was $1.2-1.3$ [49]. The membranes were regenerated after use by dipping for 2 days in ethanol plus 2 days in toluene, followed by heating at $500{ }^{\circ} \mathrm{C}$ for $30 \mathrm{~min}$ in an electric muffle furnace (KM420, Advantec). The membrane homogenizer used was an external-pressure type micro kit (Model MG-20-5, Kiyomoto Iron Works, Ltd., Japan) with an effective membrane length of $12 \mathrm{~mm}$, an effective membrane area of $3.75 \mathrm{~cm}^{2}$, and a batch volume of 100 $\mathrm{mL}$ (Fig. 1A). The pressurized coarse emulsion was fed at the shell side of the module and the product emulsion was collected from the interior of the membrane tube, as shown in Fig. 1C.

\subsection{Experimental set-up and emulsification procedure}

In this work, $\mathrm{W}_{1} / \mathrm{O} / \mathrm{W}_{2}$ emulsions were prepared by a two-step process, using the procedure described in our previous work [44]. A submicron $\mathrm{W}_{1} / \mathrm{O}$ emulsion was first prepared using a high-shear dispersing machine (Ultra Turrax ${ }^{\circledR}$ Model T25, IKA Works, Inc., Wilmington, USA) at 24,000 rpm for $5 \mathrm{~min}$. The mean size of inner water droplets 
was in the range of $0.37-0.75 \mu \mathrm{m}$ depending on the water phase content, $\varphi_{\mathrm{i}}$, as shown in Tab. 2. This $\mathrm{W}_{1} / \mathrm{O}$ emulsion was gently mixed with the outer aqueous phase $\mathrm{W}_{2}$ using a stirring bar to prepare a coarse polydispersed $\mathrm{W}_{1} / \mathrm{O} / \mathrm{W}_{2}$ emulsion. The coarse emulsion was then homogenized by passing 5-6 times through SPG membrane under the driving pressure of 60-150 kPa, built up with compressed $\mathrm{N}_{2}$ (Fig 1B). The product emulsion was collected into a beaker placed on an electronic balance (PR 5002, Mettler Toledo). The balance was interfaced to a PC computer to collect time vs. mass data using WIN for METTLER software.

\subsection{Measurement of particle size distribution}

Particle size distribution in the samples was determined using a Shimadzu model SALD-2000 laser diffraction particle size analyzer, with the resolution of 50 channels in the measuring range of $0.03-280 \mu \mathrm{m}$. The mean particle size was expressed as the $d_{50}$ diameter, which is a particle diameter corresponding to the cumulative particle volume of 50 vol. \%. Micrographs of emulsion droplets were taken using an Olympus PM-CP-3 Polaroid camera attached to an Olympus BH-2 optical microscope.

\subsection{Measurement of encapsulation efficiency of the marker substance}

The encapsulation efficiency was determined by separating the $\mathrm{W}_{1} / \mathrm{O}$ drops from the outer water phase in the multiple emulsion using disposable Vivaspin centrifugal ultrafilters (Sartorius AG, Goettingen, Germany). These ultrafilters are equipped with polyethersulfone (PES) membranes with a mean pore size of $0.2 \mu \mathrm{m}$ and an effective area of $2.5 \mathrm{~cm}^{2}$. Ultrafiltration was carried out at $1300 \mathrm{rpm}$ for $30-60 \mathrm{~min}$ using a Kubota centrifuge (model 5400) equipped with a swinging bucket rotor (RS-720M). 
One $\mathrm{mL}$ of filtrate was diluted to $10 \mathrm{~mL}$ with distilled water and the Ca concentration in the solution was then measured using a Seiko SPS 1500VR inductively coupled plasma (ICP) emission spectrophotometer. In order to determine the total Ca content in the multiple emulsion, $10 \mathrm{~mL}$ of the feed emulsion was mixed with acetone in the ratio of 1:1, followed by vigorous stirring for $2 \mathrm{~h}$, which caused the emulsion to completely break down into two separate phases. Acetone was completely removed from the emulsion by evaporation at $50^{\circ} \mathrm{C}$ and distilled water was added to the broken emulsion to bring sample to the initial volume of $10 \mathrm{~mL}$. One $\mathrm{mL}$ of the water phase in the broken emulsion was diluted to $10 \mathrm{~mL}$ with distilled water and the Ca concentration in the solution was then measured by the ICP analysis.

The encapsulation efficiency (Y) was expressed as the fraction of calcium that remained encapsulated within the water droplets after membrane homogenization:

$$
\mathrm{Y}=\frac{\mathrm{M}_{\mathrm{i}}-\mathrm{M}_{\mathrm{o}}}{\mathrm{M}_{\mathrm{i}}}
$$

where $M_{i}$ is the mass of calcium initially present in the inner water droplets and $M_{o}$ is the mass of calcium present in the outer water phase in the $\mathrm{W}_{1} / \mathrm{O} / \mathrm{W}_{2}$ emulsion after homogenization. If it is assumed that the marker is released due to expulsion of the inner water droplets during formation of the $\mathrm{W}_{1} / \mathrm{O} / \mathrm{W}_{2}$ emulsion, the mass of calcium initially present in the inner water droplets is given by:

$$
\mathrm{M}_{\mathrm{i}}=\mathrm{C}_{1}\left(\mathrm{~V}_{\mathrm{o}}+\mathrm{V}_{\mathrm{i}}\right)=\mathrm{C}_{1}\left[\mathrm{~V}_{\mathrm{WO}} \frac{1-\varphi_{\mathrm{o}}}{\varphi_{\mathrm{o}}}+\mathrm{V}_{\mathrm{wO}} \varphi_{\mathrm{i}}\right]
$$

The mass of Ca present in the outer water phase in the $\mathrm{W}_{1} / \mathrm{O} / \mathrm{W}_{2}$ emulsion after homogenization is then given by:

$$
\mathrm{M}_{\mathrm{o}}=\mathrm{C}_{2}\left[\mathrm{~V}_{\mathrm{o}}+\mathrm{V}_{\mathrm{i}}(1-\mathrm{Y})\right]=\mathrm{C}_{2}\left[\mathrm{~V}_{\mathrm{wO}} \frac{1-\varphi_{\mathrm{o}}}{\varphi_{\mathrm{o}}}+\mathrm{V}_{\mathrm{wO}} \varphi_{\mathrm{i}}(1-\mathrm{Y})\right]
$$


Here, $V_{i}, V_{o}$ and $V_{\text {wo }}$ are the volume of the inner water phase, the volume of the outer water phase, and the volume of the $\mathrm{W}_{1} / \mathrm{O}$ drops in the $\mathrm{W}_{1} / \mathrm{O} / \mathrm{W}_{2}$ emulsion, respectively. In addition, $\mathrm{C}_{1}$ is the concentration of $\mathrm{Ca}$ in the water phase of broken emulsion after adjusting the emulsion volume to the initial value and $\mathrm{C}_{2}$ is the concentration of $\mathrm{Ca}$ in the filtrate, respectively. Substitution of Eqs. (2) and (3) into Eq. (1) gives:

$$
\mathrm{Y}=\frac{1-\frac{\mathrm{C}_{2}}{\mathrm{C}_{1}}}{1-\frac{\mathrm{C}_{2}}{\mathrm{C}_{1}}\left[\frac{\varphi_{\mathrm{i}} \varphi_{\mathrm{o}}}{1-\varphi_{\mathrm{o}}\left(1-\varphi_{\mathrm{i}}\right)}\right]}
$$

In the remainder of this study, we express the encapsulation efficiency as a percentage: $\%$ encapsulation efficiency $=100 \mathrm{Y}$.

\section{Results and discussion}

\subsection{Effect of volume fraction of inner and outer droplets}

Fig. 2 illustrates the influence of volume fraction of inner and outer droplets on the entrapment efficiency of the marker in freshly prepared product emulsions. As can be seen, the encapsulation efficiency was not significantly reduced after 5 passes in comparison with that in a single-pass process, although the mean size of outer droplets decreased from 9.7 to $6.4 \mu \mathrm{m}$, as shown in Fig. 3. At the volume fraction of inner droplets of $\varphi_{i}=0.3$, the encapsulation efficiency was reduced from 97-98 \% in coarsely emulsified feed emulsions to 83-84 \% in homogenized emulsions after 5 passes, but a great majority of this reduction occurred in the first pass. It indicates that for the given mean pore size of $10.7 \mu \mathrm{m}$, the repeated passes led to a substantial decrease of the size of outer drops without any significant detrimental effect on the encapsulation efficiency. The results shown in Figs. 2 and 3 were obtained at $\Delta \mathrm{p}_{\mathrm{tm}}=150 \mathrm{kPa}$, which was a 
maximum transmembrane pressure applied in this work. At smaller transmembrane pressures it is reasonable to expect greater entrapment efficiencies than those in Fig. 2. Shima et al. [50] obtained the encapsulation efficiency of a hydrophilic fluorescent marker (1,3,6,8-Pyrenetetrasulfonic acid tetrasodium salt (PSTA)) greater than $90 \%$ in the homogenization of a $\mathrm{W} / \mathrm{O} / \mathrm{W}$ coarse emulsion through disposable cellulose acetate filters with a mean pore size of 0.7-3 $\mu \mathrm{m}$. Sugiura et al. [22] estimated the entrapment efficiency of calcein (a fluorescent dye) in W/O/W emulsions prepared by microchannel emulsification to be approximately $91 \%$.

The encapsulation efficiency was only $60 \%$ at $\varphi_{i}=0.5$, because the inner water droplets at $\varphi_{\mathrm{i}}=0.5$ were larger and less uniform than at $\varphi_{\mathrm{i}}=0.3$, as shown in Figures 4A and 4B and in Table 2. As suggested by Mine at al. [19], the concentration of inner droplets should be between 30 and 50 vol\% to obtain a stable double emulsion and the pore size of SPG membrane must be no less than twice the diameter of the inner droplets. At $\varphi_{i}=0.5$ this condition is not satisfied for all inner droplets and all pores. E.g., some $5 \mathrm{vol} \%$ of the inner droplets were larger than $1.3 \mu \mathrm{m}$ at $\varphi_{\mathrm{i}}=0.5$, whereas some 0.91 vol\% of the pores were smaller than $2.6 \mu \mathrm{m}$. On the other hand, at $\varphi_{\mathrm{i}}=0.3$ all inner water droplets were smaller than $1.3 \mu \mathrm{m}$ and the mean particle size was much lower than at $\varphi_{i}=0.3$, as shown in Table 2 . Therefore, the passage of inner droplets at $\varphi_{\mathrm{i}}=0.5$ through some of the pores may lead to their expulsion from the outer drops. It is interesting to note that for the conditions as in Figs. 4A and 4B, after first pass through the membrane the particle size distribution of the outer drops in the product emulsion closely corresponds to the pore size distribution. Using polycarbonate membranes with a mean pore size of 0.7-2 $\mu \mathrm{m}$ to produce polymer-stabilized W/O/W emulsions, Yafei et al. [45] found that after 5 passes the average size of outer drops was close to the mean 
pore size of the membrane. For smaller pore sizes, more passes are generally needed to reduce the mean particle size to the mean pore size. The mean particle size in coarsely emulsified feed emulsions was roughly $70 \mu \mathrm{m}$ and the minimum particle size was higher than the mean pore size.

Fig. 3 shows that the mean size of outer drops was unaffected by the volume fraction of inner droplets in the $\varphi_{i}$ range of $0.3-0.5$. In all subsequent experiments the volume fraction of inner droplets in outer drops was kept constant at $\varphi_{\mathrm{i}}=0.3$.

\subsection{Effect of interfacial tension}

Dynamic interfacial tension at oil-water interfaces greatly effects the droplet formation behavior in direct membrane emulsification [51-52] and droplet break up in premix membrane homogenization [53]. Fig. 5 shows the dynamic interfacial tension at oil-aqueous phase interface, measured by the membrane bursting method [54] for two different compositions of the oil phase (pure soybean oil or a W/O emulsion). The distance between a bursting membrane and the interface was $10 \mathrm{~mm}$, so that the rate of diffusion of emulsifier molecules from the bulk solution to the interface was negligible in comparison with the rate of their adsorption onto the interface, as suggested by Stang et al. [54]. The frequency of data acquisition was $100 \mathrm{~Hz}$ and the curves were obtained by a sigmodial fit. The interfacial tension at the interface between a pure soybean oil and $0.5 \mathrm{wt} \%$ Tween 80 solution decreased from $\gamma_{\mathrm{o}}=19.9 \mathrm{mN} / \mathrm{m}$ to $\gamma_{\infty}=9.0 \mathrm{mN} / \mathrm{m}$ in 3 s. The $\gamma$ value at the interface between a W/O emulsion and the same emulsifier solution decreased from 9.5 to $7.0 \mathrm{mN} / \mathrm{m}$ in $2.7 \mathrm{~s}$. The interfacial tension was lower than that for the pure oil because PGPG was dissolved in oil. The equilibrium interfacial tensions deduced by the membrane bursting method were in a good agreement with the $\gamma_{\infty}$ values 
determined by the drop volume method, as shown in Tab. 3 .

The effect of the interfacial tension on the transmembrane flux and mean particle size in the production of O/W emulsions is shown in Figs. 6 and 7. The residence time of emulsion within a membrane is given by: $\tau_{\mathrm{R}}=\delta \varepsilon / \mathrm{J}$, where $\delta$ and $\varepsilon$ are the membrane thickness and porosity, and $\mathrm{J}$ is the transmembrane flux. For pure soybean oil as a dispersed phase and the conditions as in Figs. 6 and 7, $\tau_{\mathrm{R}}=0.17-0.45 \mathrm{~s}$, which means that $\tau_{\mathrm{R}}<3 \mathrm{~s}$ and the equilibrium interfacial tension was not established at newly formed interfaces during homogenization. The mean particle size was significantly smaller at the lower interfacial tension, as shown in Fig. 6. Patty and Frisken postulated a simple model of repeated extrusion of coarse vesicle suspension through polycarbonate membrane filters [55]. This model predicts that the final vesicle size should be directly proportional to the square root of the equilibrium interfacial tension, which is in a good agreement with our results after 5 passes, on the condition that the $\gamma_{\infty}$ values from Tab. 3 determined by the drop volume method are used for calculation. However, a precaution should be taken, since the equilibrium interfacial tensions were not established in our experiments.

Large oil droplets moving through the pores with a radius $R_{p}$ are separated from the hydrophilic pore walls by a lubrication layer of continuous phase [53]. As the transmembrane flux increases, the thickness of the lubrication layer increases and the radius $R_{0}$ of oil cylinders decreases, until they break up into smaller pieces when $2 \pi R_{0}<$ $\lambda$, where $\lambda$ is the Raylegh-Plateau length. The thickness of the lubrication layer is directly proportional to $\mathrm{R}_{\mathrm{p}}\left(\eta_{\mathrm{c}} \mathrm{v} / \gamma\right)^{2 / 3}$ [56], where $\eta_{\mathrm{c}}$ is the continuous phase viscosity, $\mathrm{v}$ is the droplet velocity inside the pores, and $\gamma$ is the interfacial tension. Therefore, the tendency of droplets to break up increases with increasing the continuous phase 
viscosity and transmembrane flux and with decreasing the interfacial tension, which is consistent with our results in Figs. 6 and 7. As shown in Fig. 6, the particle size distribution was much broader at the lower interfacial tension, which was a consequence of the formation of small satellite droplets.

The transmembrane flux was much higher at the lower interfacial tension, as can be seen in Fig. 7. The role of transmembrane pressure is to provide a driving force for emulsion flow inside the pores and to effect breakup of outer drops [44]:

$$
\Delta \mathrm{p}_{\mathrm{tm}}=\underbrace{\eta_{\text {pore }}\left(\mathrm{R}_{\mathrm{m}}+\mathrm{R}_{\mathrm{f}, \mathrm{i}}\right) \mathrm{J}_{\mathrm{i}}}_{\Delta \mathrm{p}_{\text {flow }}}+\underbrace{\mathrm{C} \varphi_{\mathrm{o}} \gamma\left(1 / \mathrm{d}_{\mathrm{i}}-1 / \mathrm{d}_{\mathrm{i}-1}\right)}_{\Delta \mathrm{p}_{\text {break }}}
$$

where $C$ is a constant, $\eta_{\text {pore }}$ is the emulsion viscosity in pores which differs from the bulk emulsion viscosity, $\mathrm{J}_{\mathrm{i}}$ and $\mathrm{d}_{\mathrm{i}}$ are the transmembrane flux and the final mean particle size of the ith pass, $R_{m}$ is the hydraulic resistance of clean membrane, and $R_{f, i}$ is the overall fouling resistance during the ith pass. The fouling resistance is a consequence of the accumulation of droplets on the membrane surface (external fouling) and inside the pores (internal fouling). The increase in flux in the subsequent passes can be explained by two main reasons: (i) As the number of passes increases, less and less energy is used for droplet breakup, because the mean droplet size is less and less reduced tending to a limiting minimum value, and thus both $\Delta \mathrm{p}_{\text {flow }}$ and $\mathrm{J}_{\mathrm{i}}$ increases; (ii) As the mean droplet size decreases, the accumulation of droplets on the membrane surface and in the pores decreases and the membrane fouling is less pronounced. At lower interfacial tensions, $\Delta \mathrm{p}_{\text {break }}$ in Eq. (5) has a lower value, which results in higher fluxes, as shown in Fig. 7. In addition, the emulsion viscosity in pores is closely related to the dissipation of energy for droplet deformation as a result of interactions with the walls. At the lower interfacial tension, the energy losses due to droplet deformation are less significant, which results 
in the higher limiting transmembrane flux, as can be seen in Fig. 7. The limiting flux is given by: $\mathrm{J}_{\lim }=\Delta \mathrm{p}_{\mathrm{tm}} /\left[\eta_{\text {pore }}\left(\mathrm{R}_{\mathrm{m}}+\mathrm{R}_{\mathrm{f}, \lim }\right)\right]$.

\subsection{Effect of continuous phase viscosity}

Fig. 8 shows the effect of continuous phase viscosity on the transmembrane flux at two different pressures and disperse phase contents. At $\varphi_{\mathrm{o}}=20 \mathrm{vol} \%$ and $n=5$, as the continuous phase viscosity increased from 1 to $126 \mathrm{mPa} \cdot \mathrm{s}$, the flux decreased by a factor of 16 and 9 at $\Delta \mathrm{p}_{\mathrm{tm}}=150$ and $100 \mathrm{kPa}$, respectively. The lower flux at the higher continuous phase viscosity is a consequence of the higher emulsion viscosity in pores, which is in agreement with Eq. (5). At $\eta_{\mathrm{c}}=1 \mathrm{mPa} \cdot \mathrm{s}$ and $\varphi_{\mathrm{o}}=20 \mathrm{vol} \%$, the flux in the fifth pass was directly proportional to the pressure, indicating that the limiting fouling resistance remained constant over the pressure range of $100-150 \mathrm{kPa}$. At $\eta_{\mathrm{c}}=126$ $\mathrm{mPa} \cdot \mathrm{s}$, the increase in flux was over-proportional to the pressure indicating that the fouling resistance was smaller at $150 \mathrm{kPa}$ than that at $100 \mathrm{kPa}$. At the higher pressure, the flow velocity inside the pores was higher and the retention of droplets within the membrane was probably less pronounced. Under the same conditions, the flux was substantially lower at the higher disperse phase content, which was a consequence of both the higher emulsion viscosity $\eta_{\text {pore }}$ and the higher $\Delta \mathrm{p}_{\text {break }}$ term in Eq. (5).

As can be seen in Fig. 9, the droplets of resultant multiple emulsions were smaller at the higher continuous phase viscosity, in spite of the lower transmembrane fluxes. It can be attributed to a higher shear stress of continuous phase in the pores at $\eta_{\mathrm{c}}=126$ $\mathrm{mPa} \cdot \mathrm{s}$. In fact, the tendency of droplets to break up into smaller pieces is governed by the product $\eta_{\mathrm{c}} \mathrm{J}$, which is proportional to the wall shear stress of continuous phase in pores, $\sigma_{\mathrm{w}, \text { pore }}$. In a first approximation, $\sigma_{\mathrm{w}, \text { pore }}$ is given by [44]: 


$$
\sigma_{\mathrm{w}, \text { pore }}=8 \eta_{\mathrm{c}} \mathrm{J} \xi /\left(\varepsilon \mathrm{d}_{\mathrm{p}}\right)
$$

In this work, the mean pore tortuosity $\xi$ was calculated from the equation [49]:

$$
\xi=\left(\frac{\mathrm{R}_{\mathrm{m}} \varepsilon \mathrm{d}_{\mathrm{p}}^{2}}{32 \delta_{\mathrm{m}}}\right)^{0.5}
$$

For the membrane with $d_{p}=10.7 \mu \mathrm{m}$, the hydraulic resistance determined from pure water permeability data was $\mathrm{R}_{\mathrm{m}}=6.79 \cdot 10^{8} \mathrm{~m}^{-1}$, the wall porosity $\varepsilon$ determined by $\mathrm{Hg}$ porosimetry was 0.552 , and the wall thickness $\delta_{\mathrm{m}}$ was $795 \mu \mathrm{m}$, from which $\xi=1.3$. At $\Delta \mathrm{p}_{\mathrm{tm}}=150 \mathrm{kPa}, \varphi_{\mathrm{o}}=20 \mathrm{vol} \%$ and $\mathrm{n}=5$, Eq. (6) then yields $\sigma_{\mathrm{w} \text {,pore }}=80$ and $1180 \mathrm{~Pa}$ for $\eta_{\mathrm{c}}=1$ and $126 \mathrm{mPa} \cdot \mathrm{s}$, respectively. Therefore, $\sigma_{\mathrm{w} \text {,pore }}$ was much higher at the higher continuous phase viscosity, which resulted in the smaller mean particle sizes, as shown in Fig. 9. In the general case, the increase of $\eta_{c}$ can cause the product $\mathrm{J} \eta_{\mathrm{c}}$ to either inrease or decrease and thus, the tendency of droplets to break up may either be higher or lower, depending on the relative variations of $\mathrm{J}$ and $\eta_{\mathrm{c}}$.

It can be seen in Fig. 8 and 9 that at $\Delta \mathrm{p}_{\mathrm{tm}}=150 \mathrm{kPa}, \eta_{\mathrm{c}}=1 \mathrm{mPa} \cdot \mathrm{s}$, and $\varphi_{\mathrm{o}}=1$ vol\%, a transmembrane flux of $229 \mathrm{~m}^{3} \mathrm{~m}^{-2} \mathrm{~h}^{-1}$ was reached after three passes and yet, the resultant droplets were rather uniform with a span of particle size distribution of 0.34 . It is the highest flux ever reported in any membrane emulsification study so far. As a comparison, the maximum transmembrane flux reported by Suzuki et al. [39-40] was 13 $\mathrm{m}^{3} \mathrm{~m}^{-2} \mathrm{~h}^{-1}$ and a minimum span factor was 0.4. In direct cross-flow membrane emulsification, the maximum disperse phase flux of $2.5 \mathrm{~m}^{3} \mathrm{~m}^{-2} \mathrm{~h}^{-1}$ was reported by Abrahamse et al. [37] in the production of O/W emulsions using a micro-engineered membrane, but the obtained droplets were highly polydisperse. A typical dispersed 
phase flux in direct membrane emulsification is lower than $0.1 \mathrm{~m}^{3} \mathrm{~m}^{-2} \mathrm{~h}^{-1}$, which is a main disadvantage of this technique.

\subsection{Effect of pore size and comparison with direct membrane emulsification}

As presented in Fig. 10, the mean particle size increased with increasing the mean pore size of SPG membrane. However, the ratio of mean particle size to the mean pore size in premix emulsification decreased with increasing the pore size, as shown in Fig. 11. As the mean pore size varied from 5.4 to $20.3 \mu \mathrm{m}$, the ratio $\mathrm{d}_{50} / \mathrm{d}_{\mathrm{p}}$ was in the range from 1.51 to 0.98 after first pass and from 1.25 to 0.68 after five passes. In direct SPG membrane emulsification, $\mathrm{d}_{50} / \mathrm{d}_{\mathrm{p}}$ was 3.1-3.7 and was independent on the mean pore size. The mean $d_{50} / d_{p}$ value of 3.46 found here is in an excellent agreement with the value reported earlier in production of O/W emulsions using cross-flow SPG membrane emulsification [30, 32]. Direct membrane emulsification was carried out in this work using a commercial internal pressure type micro kit (type MN-20, SPG Technology, Sadowara, Japan). The shear stress at the membrane surface was developed by a stirring bar rotating at $400 \mathrm{rpm}$ in a $100 \mathrm{~mL}$ glass beaker. We also applied the stirring speeds higher than $400 \mathrm{rpm}$, but did not notice any significant difference between the results at $400 \mathrm{rpm}$ and above. It is known that the effect of wall shear stress on the particle size distribution is less and less significant as the wall shear increases. We believe that the threshold wall shear stress was exceeded at $400 \mathrm{rpm}$, so the resultant particle size distribution was unaffected by the further increase of the stirring speed. The oil flux was 2-17 $\mathrm{Lm}^{-2} \mathrm{~h}^{-1}$, which was 3-4 orders of magnitude smaller than the transmembrane flux in repeated premix emulsification and a span of particle size distribution was 0.3260.367, which was withing the range of span values in premix emulsification under 
optimal conditions (0.276-0.444). It should be noted that the wall shear stress in stirring membrane emulsification is not uniformly distributed over the whole membrane surface and as a result, the span of particle size distribution is generally higher than in cross membrane emulsification. In cross SPG membrane emulsification, under optimal conditions the span of the particle size distribution is often below 0.3 [21-30].

The mean particle size in repeated premix emulsification can precisely be tuned over a wide range by adjusting the pore size, transmembrane pressure, and the number of passes. Fig. 12 shows that multiple emulsions with almost the same mean particle size and particle size distribution were prepared using SPG membranes with three different mean pore sizes $(5.4,7.6$, and $10.7 \mu \mathrm{m})$. In the case of the $5.4 \mu \mathrm{m}$-membrane, a single pass at relatively low transmembrane flux of $1.6 \mathrm{~m}^{3} \mathrm{~m}^{-2} \mathrm{~h}^{-1}$ was applied, so that all outer drops in the product emulsion were larger than the mean pore size. In the case of the $7.6 \mu \mathrm{m}$-membrane, four passes at the moderate flux of $4.5 \mathrm{~m}^{3} \mathrm{~m}^{-2} \mathrm{~h}^{-1}$ in the final pass were applied to obtain a multiple emulsion with the same particle size distribution. In the case of the $10.7 \mu \mathrm{m}$-membrane, two passes at relatively high transmembrane flux were applied, so that almost all outer drops in the product emulsion were smaller than the pore size, but the mean particle size and particle size distribution were almost the same as in the former cases. Using the same membranes with $d_{p}=5.4-10.7 \mu \mathrm{m}$, the droplets with a mean particle size of 19.5-32 $\mu$ m were obtained by direct emulsification.

The variation of mean particle size and particle size distribution with time was examined during stationary storage of multiple emulsion samples in a glass cylinder at room temperature $\left(20-25^{\circ} \mathrm{C}\right)$. Because of relatively large particle size, the samples formed a dense creamed layer after several hours, so that almost over the whole storage time the droplets were highly concentrated in a creamed layer. As a result, the initial 
droplet concentration did not affect the emulsion stability, but only the creamed layer thickess. The mean size of outer drops did not change significantly after one week, as shown in Fig. 13, but the span values increased from 0.28 in fresh samples to 0.43-0.47 in 7-day-old samples.

\section{Conclusions}

Preparation of multiple emulsions using repeated premix SPG emulsification has been investigated in this work. The mean particle size decreased with decreasing the pore size and with increasing the product $\eta_{\mathrm{c}} \mathrm{J}$, where $\eta_{\mathrm{c}}$ is the continuous phase viscosity and $\mathrm{J}$ is the transmembrane flux. Under the same conditions, the higher transmembrane fluxes and smaller mean particle sizes were obtained at the lower interfacial tension. The equilibrium interfacial tension could not be established during emulsion passes and consequently, the rate of adsorption of emulsifier molecules at newly formed interfaces played an important role. The entrapment efficiency of a hydrophilic model substance was virtually independent on the number of passes and was significantly higher at the lower content of inner droplets (30 vol\%), which was a consequence of their smaller size and higher monodispersity than at 50 vol\%. At the low continuous phase viscosity, multiple emulsions with a very narrow particle size distribution ( $\operatorname{span}=0.28-0.34$ ) were obtained at the transmembrane fluxes exceeding $200 \mathrm{~m}^{3} \mathrm{~m}^{-2} \mathrm{~h}^{-1}$ in some experiments. The ratio of mean particle size to the mean pore size decreased with increasing the pore size and the number of passes and was 1.25 to 0.68 after five passes through the membrane at the wall shear stress of continuous phase of $200 \mathrm{~Pa}$. In direct emulsification using the same SPG membranes and product formulations, the particle/pore size ratio was in the range of 3.1-3.7 and the transmembrane flux was 3-4 orders of magnitude lower than 
that in premix emulsification. By choosing an appropriate set of operating conditions, it was feasible to produce multiple emulsions with the same particle size distribution using SPG membranes with different pore sizes over a wide range. These results confirm a high operation flexibility and suitability of repeated SPG membrane homogenization for controlled production of $\mathrm{W} / \mathrm{O} / \mathrm{W}$ emulsions with a high encapsulation efficiency at high production scales. 


\section{List of Symbols}

C constant in Eq. (5), -

$\mathrm{C}_{1} \quad$ concentration of marker in water phase of broken emulsion, $\mathrm{kg} \mathrm{m}^{-3}$

$\mathrm{C}_{2}$ concentration of marker in outer water phase after homogenisation, $\mathrm{kg} \mathrm{m}^{-3}$

$d_{p} \quad$ mean pore size of membrane, $m$

$d_{50} \quad$ mean particle size of emulsion, $m$

$\mathrm{J} \quad$ transmembrane flux, $\mathrm{m} \mathrm{s}^{-1}$

n number of passes through membrane, -

$\Delta \mathrm{p}_{\mathrm{tm}} \quad$ transmembrane pressure, $\mathrm{Pa}$

$\Delta \mathrm{p}_{\text {flow }} \quad$ pressure loss for overcoming flow resistances in the pores, $\mathrm{Pa}$

$\Delta \mathrm{p}_{\text {break }} \quad$ pressure loss for droplet breakup, $\mathrm{Pa}$

$\mathrm{q}_{3} \quad$ volume frequency of particles, $\mathrm{m}^{-1}$

$\mathrm{R}_{\mathrm{m}} \quad$ hydrodynamic resistance of clean membrane, $\mathrm{m}^{-1}$

$\mathrm{R}_{\mathrm{f}} \quad$ fouling resistance, $\mathrm{m}^{-1}$

span relative span factor of particle size distribution, $\left(\mathrm{d}_{90}-\mathrm{d}_{10}\right) / \mathrm{d}_{50}$, -

$\mathrm{V}_{\mathrm{i}} \quad$ volume of inner water droplets in $\mathrm{W}_{1} / \mathrm{O}$ emulsion, $\mathrm{m}^{3}$

$\mathrm{V}_{\mathrm{WO}} \quad$ volume of $\mathrm{W}_{1} / \mathrm{O}$ emulsion in $\mathrm{W}_{1} / \mathrm{O} / \mathrm{W}_{2}$ emulsion, $\mathrm{m}^{3}$

$\mathrm{V}_{\mathrm{o}} \quad$ volume of outer water phase $\left(\mathrm{W}_{2}\right)$ in $\mathrm{W}_{1} / \mathrm{O} / \mathrm{W}_{2}$ emulsion, $\mathrm{m}^{3}$

Y encapsulation efficiency, -

$\delta_{\mathrm{m}} \quad$ membrane thickness, $\mathrm{m}$

$\varepsilon \quad$ porosity of membrane wall, -

$\eta_{\text {pore }} \quad$ viscosity of emulsion in pores, Pa s

$\eta_{\mathrm{c}} \quad$ viscosity of continuous phase, $\mathrm{Pa} \mathrm{s}$

$\varphi_{\mathrm{i}} \quad$ volume fraction of inner water droplets in $\mathrm{W}_{1} / \mathrm{O}$ emulsion, - 
$\varphi_{0} \quad$ volume fraction of $\mathrm{W}_{1} / \mathrm{O}$ emulsion (outer drops) in outer water phase, -

$\gamma \quad$ dynamic (non-equilibrium) interfacial tension at oil/water interface, $\mathrm{N} \mathrm{m}^{-1}$

$\gamma_{\infty} \quad$ equilibrium interfacial tension at oil/water interface, $\mathrm{N} \mathrm{m}^{-1}$

$\sigma_{\mathrm{w}, \mathrm{pore}} \quad$ wall shear stress of continuous phase in pores, $\mathrm{Pa}$

$\xi \quad$ mean tortuosity factor of pores (the ratio of mean pore length and membrane thickness), -

\section{Subscripts}

i refers to ith pass of emulsion through membrane

\section{Acknowledgement.}

The authors wish to thank the Japan Society for the Promotion of Science (JSPS), Tokyo, Japan for the financial support of this work. The measurements of the dynamic interfacial tensions were carried out at the Institute of Food Process Engineering in Karlsruhe in co-operation with Prof. Helmar Schubert. G.T.V. acknowledges financial support from the Alexander von Humboldt Foundation for this short stay. G.T.V. also acknowledges financial support from the Ministry of Science and Environmental Protection of the Republic of Serbia. 


\section{References}

[1] N. Garti, Double emulsions - scope, limitations and new achievements, Colloid. Surf. A, 123-124 (2000) 233.

[2] C. Oh, S.C. Chung, S.I. Shin, Y.C. Kim, S.S. Im and S.G. Oh, Distribution of macropores in silica particles prepared by using multiple emulsions, J. Colloid Interface Sci., 254 (2002) 79.

[3] H. Okochi and M. Nakano, Preparation and evaluation of W/O/W type emulsions containing vancomycin, Adv. Drug Del. Rev., 45 (2000) 5.

[4] J.S. Lee, J.W. Kim, S.H. Han, H.S. Chang, H.H. Kang, O.S. Lee, S.G. Oh and K.D. Suh, The stabilization of L-ascorbic acid in aqueous solution and water-inoil-in-water double emulsion by controlling $\mathrm{pH}$ and electrolyte concentration, J. Cosmet. Sci., 55 (2004) 1.

[5] N. Garti, Progress in stabilization and transport phenomena of double emulsions in food applications, Lebensm.-Wiss. u.-Technol., 30 (1997) 222.

[6] M. Chakraborty, C. Bhattacharya and S. Datta, Study of the stability of W/O/Wtype emulsion during the extraction of nickel via emulsion liquid membrane, Sep. Sci. Technol., 39 (2004) 2609.

[7] B. Yordanov and L. Boyadzhiev, Pertraction of citric acid by means of emulsion liquid membranes, J. Membr. Sci., 238 (2004) 191.

[8] S.C. Lee, Comparison of extraction efficiencies of penicillin G at different w/o ratios in the emulsion liquid membrane systems with dilute polymer solutions, J. Membr. Sci., 237 (2004) 225.

[9] J. Weiss and G. Vladisavljević, Microencapsulation systems with emphasis on successful applications in foods, in D.R. Heldman (Ed.), Encyclopedia of 
Agricultural, Food, and Biological Engineering, Taylor \& Francis LLC, New York, in press.

[10] B. DeCindio and D. Cacace, Formulation and rheological characterization of reduced-calorie food emulsions, Int. J. Food. Sci. Technol., 30 (1995) 505.

[11] H.J. Liu, Y.H. Ni, W. Fei, Y. Gui, J.M. Hong, Q. Ma and X. Zheng, Fabrication of submicron $\mathrm{Cu}_{2} \mathrm{O}$ hollow spheres in an $\mathrm{O} / \mathrm{W} / \mathrm{O}$ multiple emulsions, Colloid. Surf. A, 235 (2004) 79.

[12] M. Garcia-Fuentes, D. Torres and M.J. Alonso, Design of lipid nanoparticles for the oral delivery of hydrophilic macromolecules, Colloid. Surf. B, 27 (2003) 159.

[13] G.H. Ma, H. Sone and S. Omi, Preparation of uniform-sized polystyrenepolyacrylamide composite microspheres from a $\mathrm{W} / \mathrm{O} / \mathrm{W}$ emulsion by membrane emulsification technique and subsequent suspension polymerization, Macromolecules, 37 (2004) 2954.

[14] G.T. Vladisavljević and R.A. Williams, Recent developments in manufacturing emulsions and particulate products using membranes, Adv. Colloid Interface Sci., $113(2005) 1$.

[15] J. Herrmann and R. Bodmeier, Somatostatin containing biodegradable microspheres prepared by a modified solvent evaporation method based on W/O/W-multiple emulsions, Int. J. Pharm., 126 (1995) 129.

[16] T. Kawakatsu, G. Trägårdh and C. Trägårdh, Production of W/O/W emulsions and S/O/W pectin microcapsules by microchannel emulsification, Colloid. Surf. A, 189 (2001) 257. 
[17] E. Lorenceau, A.S. Utada, D.R. Link, G. Cristobal, M. Joanicot and D.A. Weitz, Generation of polymerosomes from double emulsions, Langmuir, 21 (2005) 9183.

[18] S. Higashi, M. Shimizu, T. Nakashima, K. Iwata, F. Uchiyama, S. Tateno, S. Tamura and T. Setoguchi, Arterial-injection chemotherapy for hepatocellularcarcinoma using monodispersed poppy-seed oil microdroplets containing fine aqueous vesicles of epirubicin - initial medical application of a membraneemulsification technique, Cancer, 75 (1995) 1245.

[19] Y. Mine, M. Shimizu and T. Nakashima, Preparation and stabilization of simple and multiple emulsions using a microporous glass membrane, Colloid. Surf. B, 6 (1996) 261.

[20] S. van der Graaf, C.G.P.H. Schroën and R.M. Boom, Preparation of double emulsions by membrane emulsification - a review, J. Membr. Sci., 251 (2005) 7.

[21] G.T. Vladisavljević and H. Schubert, Influence of process parameters on droplet size distribution in SPG membrane emulsification and stability of prepared emulsion droplets, J. Membr. Sci., 225 (2003) 15.

[22] S. Sugiura, M. Nakajima, K. Yamamoto, S. Iwamoto, T. Oda, M. Satake and M. Seki, Preparation characteristics of water-in-oil-in-water multiple emulsions using microchannel emulsification, J. Colloid Interface Sci., 270 (2004) 221.

[23] I. Kobayashi, X.F. Lou, S. Mukataka and M. Nakajima, Preparation of monodisperse water-in-oil-in-water emulsions using microfluidization and straight-through microchannel emulsification, J. Am. Oil Chem. Soc., 82 (2005) 65. 
[24] D. Gladman and R. Williams, Manufacturing with membranes, TCE, 748 (2003) 32.

[25] T. Thorsen, R.W. Roberts, F.H. Arnold and S.R. Quake, Dynamic pattern formation in a vesicle-generating microfluidic device, Phys. Rev. Lett., 86 (2001) 4163.

[26] A.M. Ganan-Calvo and J.M. Gordillo, Perfectly monodisperse microbubbling by capillary flow focusing, Phys. Rev. Lett., 87 (2001) 274501.

[27] S. Okushima, T. Nisisako, T. Torii and T. Higuchi, Controlled production of monodisperse double emulsions by two-step droplet breakup in microfluidic devices, Langmuir, 20 (2004) 9905.

[28] A.S. Utada, E. Lorenceau, D.R. Link, P.D. Kaplan, H.A. Stone and D.A. Weitz, Monodisperse double emulsions generated from a microcapillary device, Science, 308 (2005) 537.

[29] Z. Nie, S. Xu, M. Seo, P.C. Lewis and E. Kumacheva, Polymer particles with various shapes and morphologies produced in continuous microfluidic reactors, J. Am. Chem. Soc., 127 (2005) 8058.

[30] G.T. Vladisavljević, U. Lambrich, M. Nakajima and H. Schubert, Production of $\mathrm{O} / \mathrm{W}$ emulsions using SPG membranes, ceramic $\alpha-\mathrm{Al}_{2} \mathrm{O}_{3}$ membranes, microfluidizer and a microchannel plate - a comparative study, Colloid. Surface. A, 232 (2004) 199.

[31] G.T. Vladisavljević and H. Schubert, Preparation of emulsions with a narrow particle size distribution using microporous $\alpha$-alumina membranes, J. Dispersion Sci. Technol., 24 (2003) 811.

[32] G.T. Vladisavljević and H. Schubert, Preparation and analysis of oil-in-water 
emulsions with a narrow droplet size distribution using Shirasu-porous-glass (SPG) membranes, Desalination, 144 (2002) 167.

[33] S.M. Joscelyne and G. Trägårdh, Membrane emulsification - a literature review, J. Membr. Sci., 169 (2000) 107.

[34] R.A. Williams, S.J. Peng, D.A. Wheeler, N.C. Morley, D. Taylor, M. Whalley and D.W. Houldsworth, Controlled production of emulsions using a crossflow membrane, Chem. Eng. Res. Des., 76A (1998) 902.

[35] T. Nakashima, M. Shimizu and M. Kukizaki, Particle control of emulsion by membrane emulsification and its applications, Adv. Drug Deliv. Rev., 45 (2000) 47.

[36] I. Kobayashi, M. Nakajima and S. Mukataka, Preparation characteristics of oil-inwater emulsions using differently charged surfactants in straight-through microchannel emulsification, Colloid. Surface. A, 229 (2003) 33.

[37] A.J. Abrahamse, R. van Lierop, R.G.M. van der Sman, A. van der Padt, and R.M. Boom, Analysis of droplet formation and interactions during cross-flow membrane emulsification, J. Membr. Sci., 204 (2002) 125.

[38] K. Suzuki, I. Shuto and Y. Hagura, Characteristics of the membrane emulsification method combined with preliminary emulsification for preparing corn oil-in-water emulsions, Food Sci. Technol. Int. Tokyo, 2 (1996) 43.

[39] K. Suzuki, I. Fujiki and Y. Hagura, Preparation of corn oil/water and water/corn oil emulsions using PTFE membranes, Food Sci. Technol. Int. Tokyo, 4 (1998) 164. 
[40] K. Suzuki, I. Fujiki and Y. Hagura, Preparation of high concentration of O/W and W/O emulsions by the membrane phase inversion emulsification using PTFE membranes, Food Sci. Technol. Int. Tokyo, 5 (1999) 234.

[41] J. Altenbach-Rehm, H. Schubert and K. Suzuki, Premix-Membranemulgieren mittels hydrophiler und hydrophober PTFE-Membranen zur Herstellung von O/W-Emulsionen mit enger Tropfengrößenverteilung, Chem. Ing. Tech., 74 (2002) 587.

[42] J. Altenbach-Rehm, K. Suzuki and H. Schubert, Production of O/W-emulsions with narrow droplet size distribution by repeated premix membrane emulsification, in: Proceed. $3^{\text {rd }}$ World Congress on Emulsions, Lyon, France, 2002, 2-B-051.

[43] S.H. Park, T. Yamaguchi and S. Nakao, Transport mechanism of deformable droplets in microfiltration of emulsions, Chem. Eng. Sci., 56 (2001) 3539.

[44] G.T. Vladisavljević, M. Shimizu and T. Nakashima, Preparation of monodisperse multiple emulsions at high production rates by multi-stage premix membrane emulsification, J. Membr. Sci., 244 (2004) 97.

[45] W. Yafei, Z. Tao and H. Gang, Structural evolution of polymer-stabilized double emulsions, Langmuir, 67 (2006) 67.

[46] H.S. Ribeiro, L.G. Rico, G.G. Badolato and H. Schubert, Production of O/W emulsions containing astaxanthin by repeated premix membrane emulsification, J. Food Sci., 70 (2005) E117.

[47] F. Olson, C.A. Hunt, F.C. Szoka, W.J. Vail and D. Papahadjopoulos, Preparation of liposomes of defined size distribution by extrusion through polycarbonate membranes, Biochim. Biophys. Acta, 557 (1979) 9. 
[48] D.J. McClements, Food Emulsions: Principles, Practice, and Techniques, CRC Press, Boca Raton, FL, 1999.

[49] G.T. Vladisavljević, M. Shimizu and T. Nakashima, Permeability of hydrophilic and hydrophobic Shirasu-porous-glass (SPG) membranes to pure liquids and its microstructure, J. Membr. Sci., 250 (2005) 69.

[50] M. Shima, Y. Kobayashi, T. Fujii, M. Tanaka, Y. Kimura, S. Adachi and R. Matsuno, Preparation of fine W/O/W emulsion through membrane filtration of coarse $\mathrm{W} / \mathrm{O} / \mathrm{W}$ emulsion and disappearance of the inclusion of outer phase solution, Food Hydrocolloids, 18 (2004) 61.

[51] S. van der Graaf, C.G.P.H. Schroën, R.G.M. van der Sman and R.M. Boom, Influence of dynamic interfacial tension on droplet formation during membrane emulsification, J. Colloid Interface. Sci., 277 (2004) 456.

[52] V. Schröder, O. Behrend and H. Schubert, Effect of dynamic interfacial tension on the emulsification process using microporous, ceramic membranes, J. Colloid Interface. Sci., 202 (1998) 334.

[53] G.T. Vladisavljević, J. Surh and J.D. McClements, Effect of emulsifier type on droplet disruption in repeated Shirasu Porous Glass membrane homogenization, Langmuir, 22 (2006) 4526.

[54] M. Stang, H. Karbstein and H. Schubert, Adsorption kinetics of emulsifiers at oilwater interfaces and their effect on mechanical emulsification, Chem. Eng. Process., 33 (1994) 307.

[55] P.J. Patty and B.J. Frisken, The pressure-dependence of the size of extruded vesicles, Biophys. J., 85 (2003) 996. 
[56] D.G. Hunter and B.J. Frisken, Effect of extrusion pressure and lipid properties on the size and polydispersity of lipid vesicles, Biophys. J., 74 (1998) 2996.

\section{TABLES}

Table 1. The composition of $\mathrm{W}_{1} / \mathrm{O} / \mathrm{W}_{2}$ emulsions prepared in this work.

Inner aqueous phase, $\mathrm{W}_{1}$
5 wt.\% PGPR dissolved in soybean oil

0.5 wt. $\%$ Tween $80+0-1$ wt. $\%$ sodium alginate +5 wt. $\%$ glucose dissolved in distilled water

$\varphi_{\mathrm{i}}=0-0.5$

Volume fraction of inner droplets $\left(\mathrm{W}_{1}\right)$

in outer drops $\left(\mathrm{W}_{1} / \mathrm{O}\right.$ emulsion)

2 wt.\% $\mathrm{CaNa}_{2}$-EDTA + 5 wt. \% glucose dissolved in distilled water

Volume fraction of outer drops in multiple emulsion

$\varphi_{0}=0.01-0.5$ 
Table 2. The properties of $\mathrm{W}_{1} / \mathrm{O}$ emulsions prepared by homomixer at $24,000 \mathrm{rpm}$ for 5 $\min$

\begin{tabular}{ccc}
\hline$\varphi_{\mathrm{i}}($ vol. \%) & $\mathrm{d}_{50}(\mu \mathrm{m})$ & Span $(/)$ \\
\hline 10 & 0.374 & 0.662 \\
30 & 0.541 & 0.538 \\
50 & 0.746 & 0.875 \\
\hline
\end{tabular}

Table 3. Equilibrium interfacial tension at different oil-aqueous phase interfaces, measured by the drop volume and membrane bursting method.

\begin{tabular}{|c|c|c|c|}
\hline Oil phase & Aqueous phase & $\begin{array}{l}\text { Drop volume } \\
\text { method } \\
\gamma_{\infty} / \mathrm{mN} / \mathrm{m}\end{array}$ & $\begin{array}{c}\text { Membrane bursting } \\
\text { method } \\
\gamma_{\infty} / \mathrm{mN} / \mathrm{m}\end{array}$ \\
\hline Pure soybean oil & Bi-distilled water & 24 & 20 \\
\hline Pure soybean oil & $\begin{array}{l}0.5 \text { wt. \% Tween } \\
80+5 \text { wt.\% } \\
\text { glucose in water }\end{array}$ & 7.2 & 9.0 \\
\hline $\begin{array}{c}\text { W/O emulsion, } \\
\varphi_{\mathrm{i}}=0.3\end{array}$ & $\begin{array}{l}0.5 \text { wt. \% Tween } \\
80+5 \text { wt.\% } \\
\text { glucose in water }\end{array}$ & 6.5 & 7.0 \\
\hline $\begin{array}{c}5 \text { wt. \% PGPR in } \\
\text { soybean oil }\end{array}$ & $\begin{array}{l}0.5 \text { wt. \% Tween } \\
80+5 \text { wt. } \% \\
\text { glucose in water }\end{array}$ & 1.1 & - \\
\hline
\end{tabular}




\section{FIGURE CAPTIONS}

Fig. 1: (A) Membrane homogenizer used in this work. (B) Schematic view of experimental setup.

Fig. 2: The variation of encapsulation efficiency with the number of passes through the membrane at different volume fractions of inner $\left(\varphi_{\mathrm{i}}\right)$ and outer $\left(\varphi_{\mathrm{o}}\right)$ droplets.

Fig. 3: The effect of volume fraction of inner droplets on the mean size of outer drops in product emulsions.

Fig. 4: Particle size distribution of emulsion droplets: (+) outer drops in feed emulsion; $(\diamond)$ outer drops in product emulsion after a single pass; $(\boldsymbol{\square})$ outer drops in product emulsion after five passes; (O) inner droplets at $\varphi_{\mathrm{i}}=0.5$; $(\bigcirc)$ inner droplets at $\varphi_{\mathrm{i}}=0.3$. Pore size distribution of the SPG membrane used is shown by a dashed line.

Fig. 5: Dynamic interfacial tension at oil-aqueous phase interface for two different compositions of oil phase (pure soybean oil or a W/O emulsion containing 5 wt\% PGPR in soybean oil as a continuous phase). The aqueous phase in both cases was 0.5 wt $\%$ Tween $80+5$ wt $\%$ glucose in bi-distilled water. The experimental $\gamma$ vs. $t$ data for pure oil are shown in the inserted figure. 
Fig. 6: The effect of the interfacial tension on the mean size and span of the particle size distribution in homogenized $\mathrm{O} / \mathrm{W}$ emulsions (continuous phase: $0.5 \mathrm{wt} \%$ Tween $80+1$ wt\% Na-alginate +5 wt\% glucose; dispersed phase: pure soybean oil or $5 \mathrm{wt} \%$ PGPR in soybean oil). The mean pore size is designated by the dashed line.

Fig. 7: The effect of the interfacial tension on the transmembrane flux (the experimental conditions as in Fig. 6).

Fig. 8: The effect of the continuous phase viscosity on the transmembrane flux at two different pressures (100 and $150 \mathrm{kPa}$ ) and the contents of outer droplets (1 and 20 vol $\%)$. Other conditions: $\varphi_{i}=30$ vol $\%, d_{p}=10.7 \mu \mathrm{m}$.

Fig. 9: The effect of the continuous phase viscosity on the mean size of outer drops. The symbols and experimental conditions are the same as in Fig. 8.

Fig. 10: The effect of the mean pore size on the mean droplet size at the constant shear stress of continuous phase inside pores of approximately $200 \mathrm{~Pa}\left(\eta_{\mathrm{c}}=126\right.$ mPas).

Fig. 11: The relationship between the mean droplet size and the mean pore size for multiple emulsions prepared using direct stirring membrane emulsification (stirring rate $=400 \mathrm{rpm})$ and repeated premix emulsification $\left(\sigma_{\mathrm{w}, \text { pore }}=200 \mathrm{~Pa}\right)$. 
Fig. 12: The size distribution of outer drops prepared using SPG membranes with different mean pore sizes under such conditions to obtain almost the same particle size distribution. The dashed line represents the mean pore size $\left(\varphi_{0}=1\right.$ $\left.\operatorname{vol} \%, \varphi_{\mathrm{i}}=30 \mathrm{vol} \%, \eta_{\mathrm{c}}=126 \mathrm{mPas}\right)$

Fig. 13: The micrographs of droplets produced by direct and repeated premix emulsification using SPG membrane with a pore size of 5.4, 7.6, and $10.7 \mu \mathrm{m}$. In the case of premix emulsification (D), the emulsions with the same particle size distribution can be produced, as shown in Fig. 12.

Fig. 14: The variation of the mean particle size and the span of particle size distribution of outer droplets during storage of multiple emulsions with different dispersed phase contents for one week at room temperature. 


\section{FIGURES}

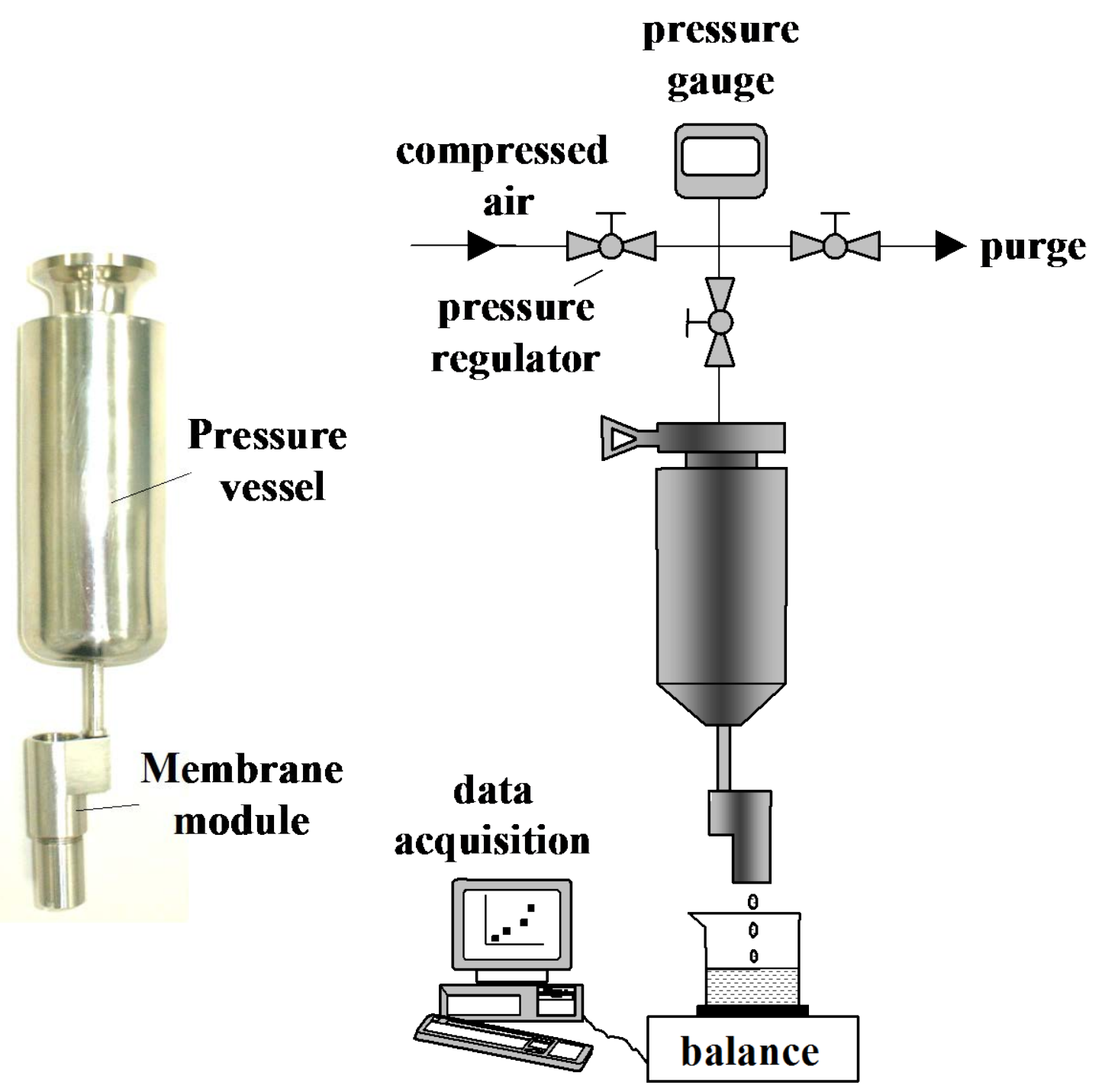

(A)

(B) 
Fig. 1: (A) Membrane homogenizer used in this work. (B) Schematic view of experimental setup.

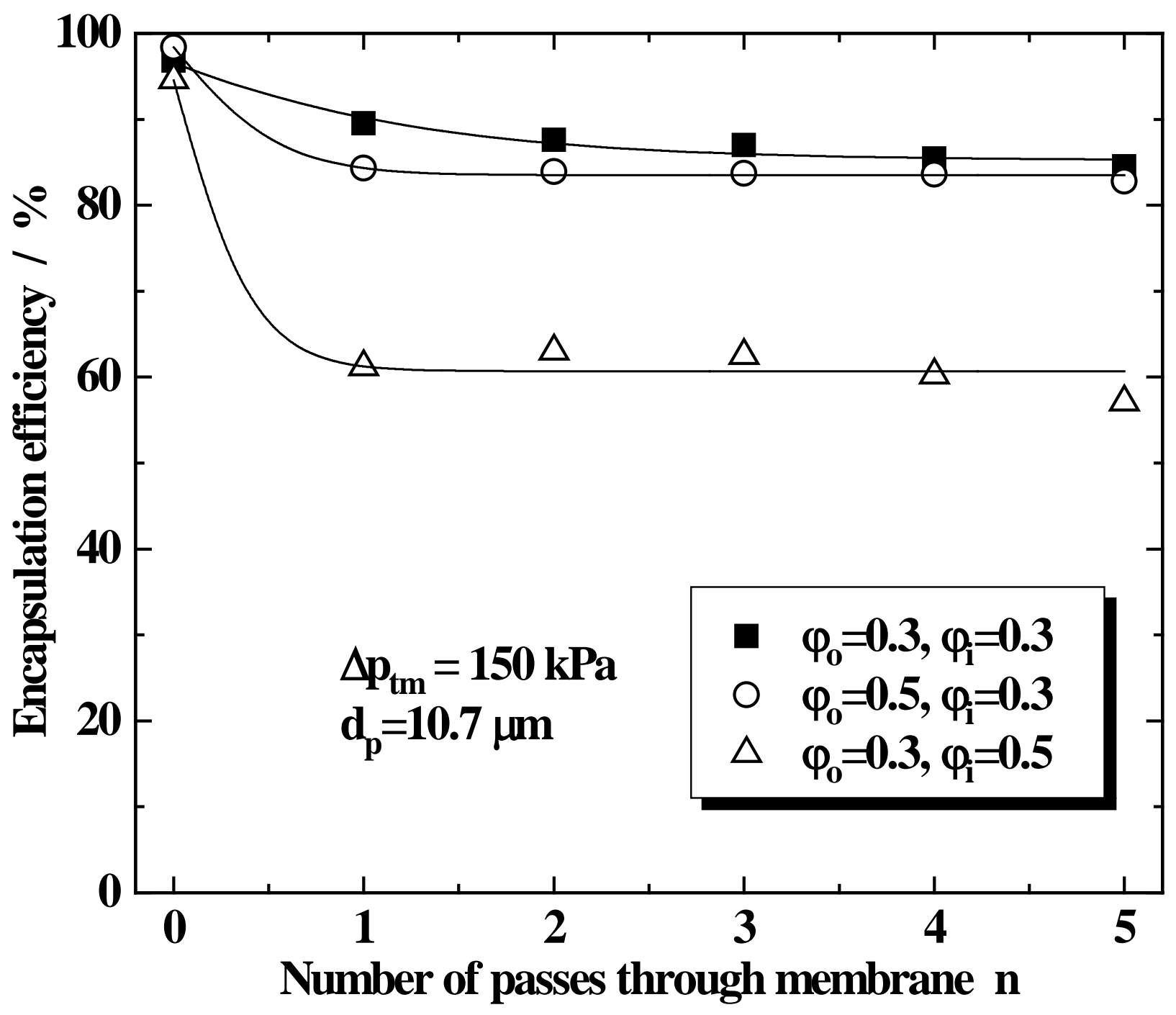


Fig. 2: The variation of encapsulation efficiency with the number of passes through the membrane at different volume fractions of inner $\left(\varphi_{i}\right)$ and outer $\left(\varphi_{0}\right)$ droplets.

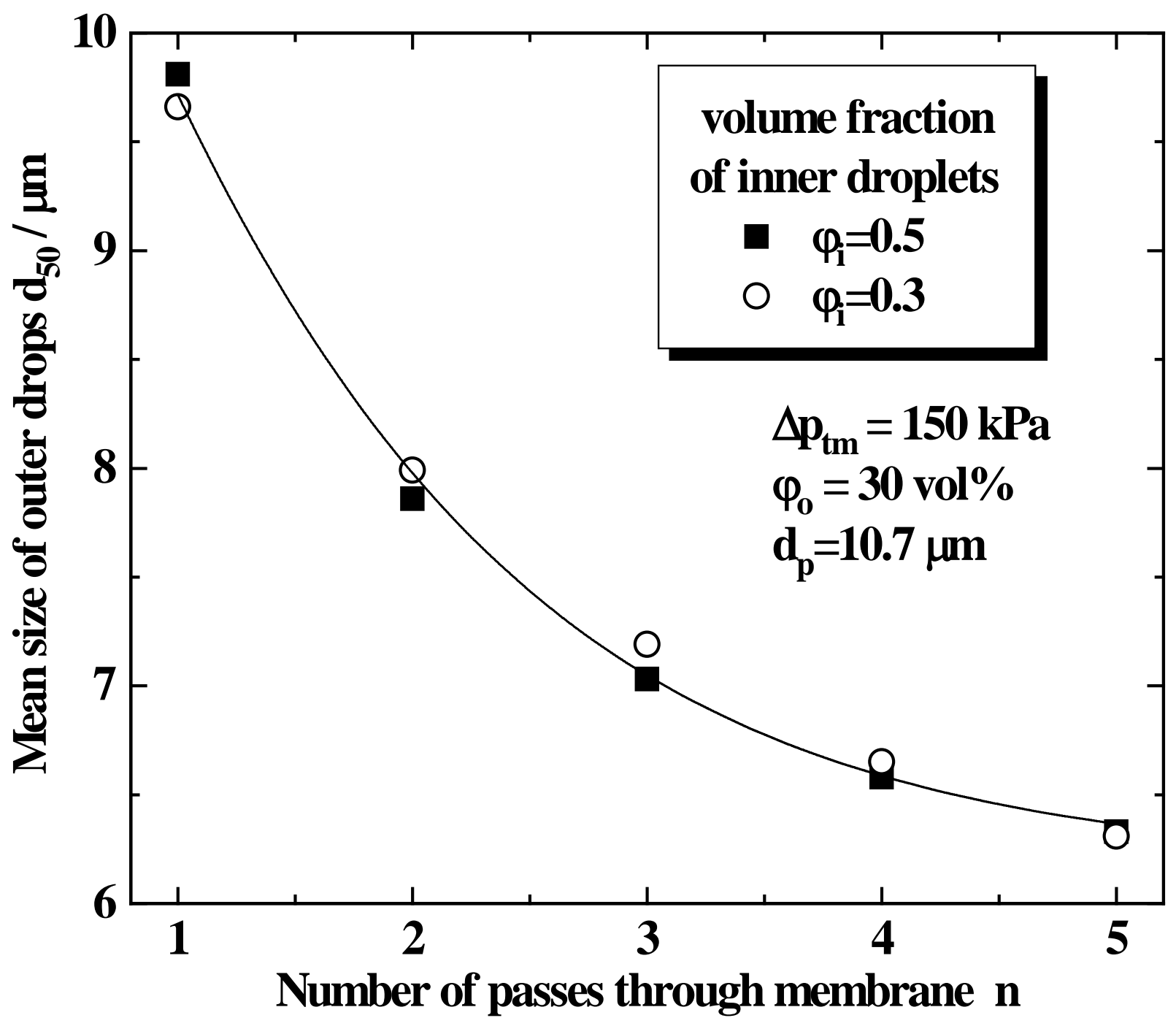


Fig. 3: The effect of volume fraction of inner droplets on the mean size of outer drops in product emulsions.

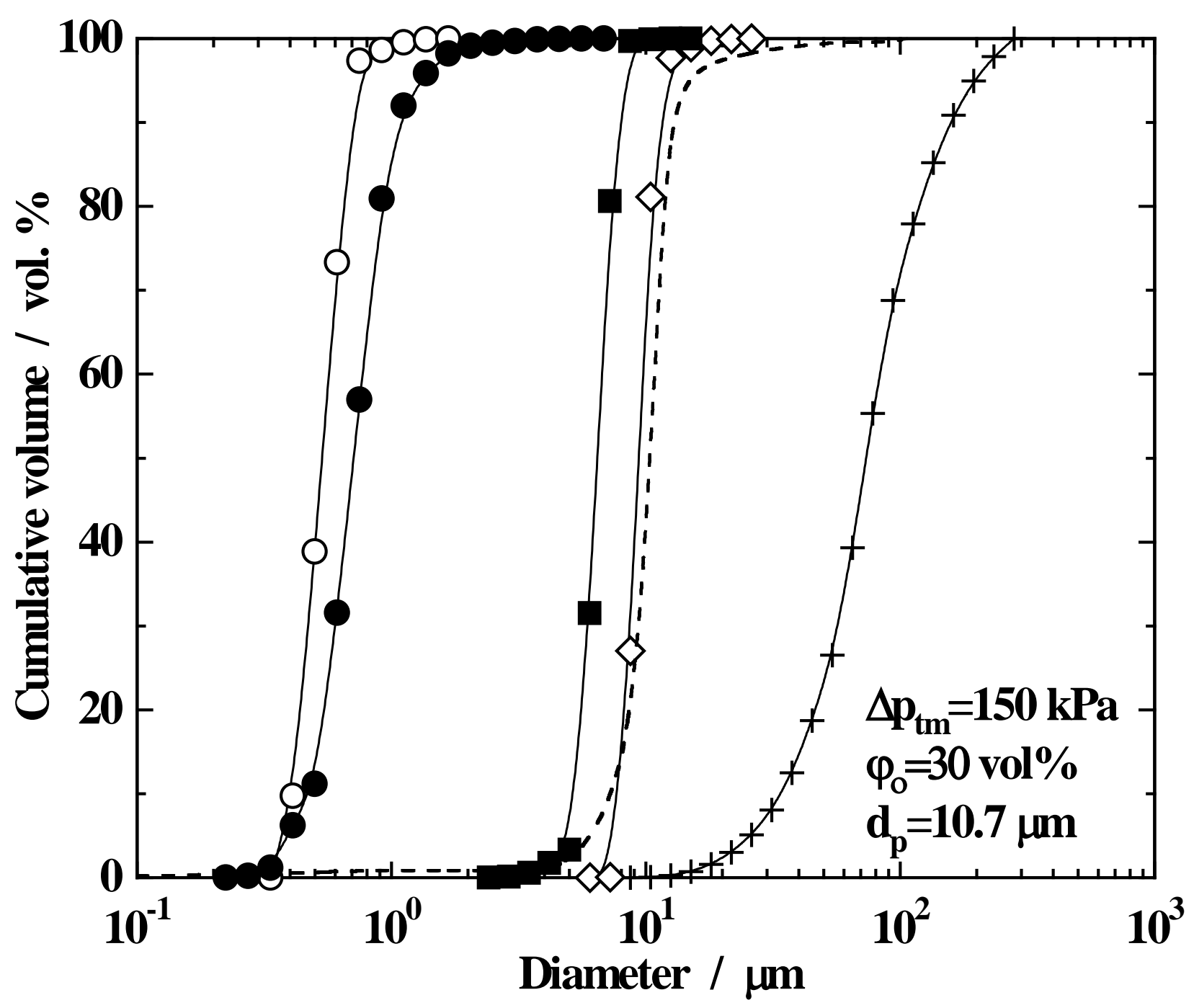


Fig. 4: Particle size distribution of emulsion droplets: (+) outer drops in feed emulsion; $(\diamond)$ outer drops in product emulsion after a single pass; $(\mathbf{\square})$ outer drops in product emulsion after five passes; $(\mathbf{O})$ inner droplets at $\varphi_{\mathrm{i}}=0.5$; $(\bigcirc)$ inner droplets at $\varphi_{\mathrm{i}}=0.3$. Pore size distribution of the SPG membrane used is shown by a dashed line.

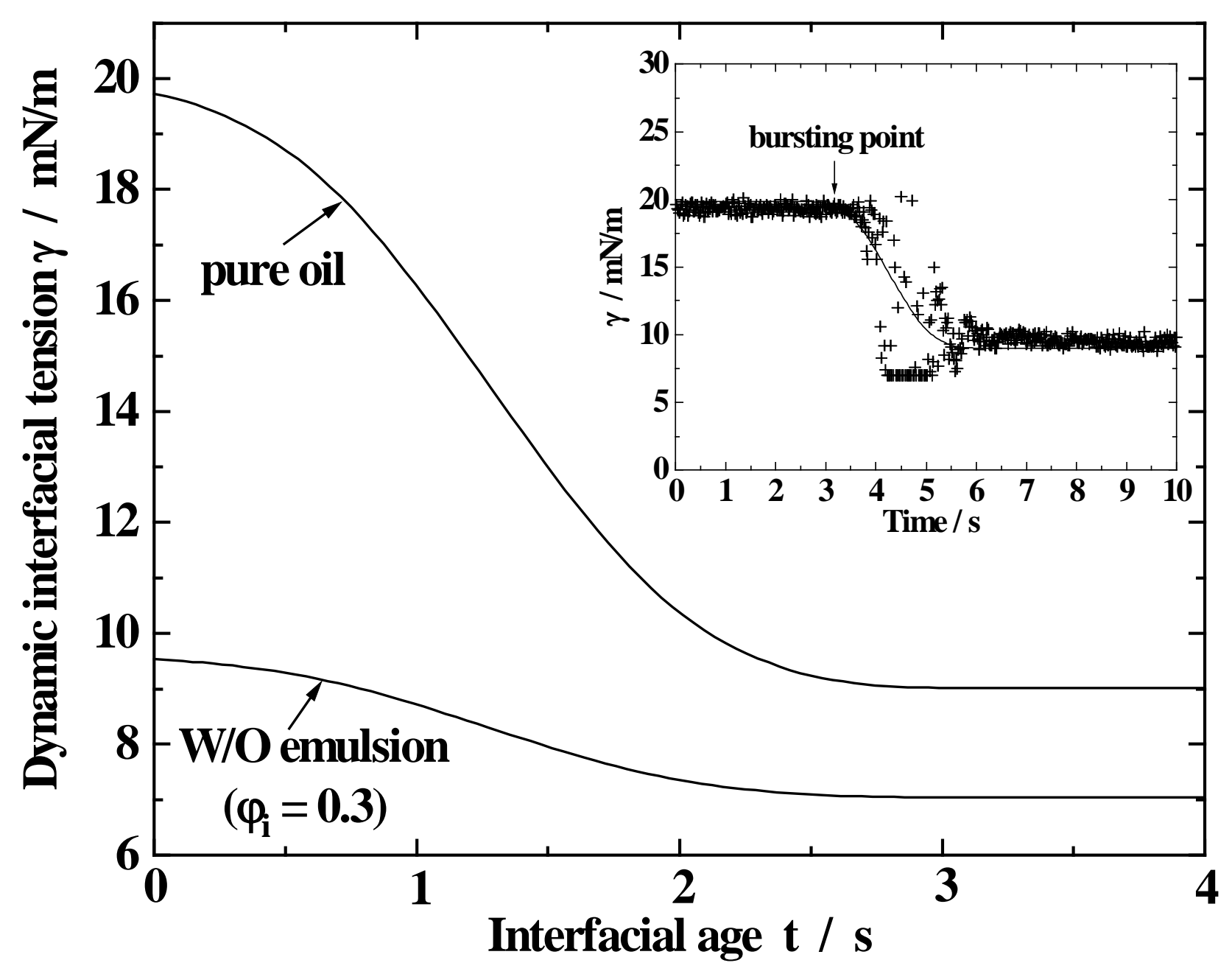


Fig. 5: Dynamic interfacial tension at oil-aqueous phase interface for two different compositions of oil phase (pure soybean oil or a W/O emulsion containing 5 wt\% PGPR in soybean oil as a continuous phase). The aqueous phase in both cases was $0.5 \mathrm{wt} \%$ Tween $80+5 \mathrm{wt} \%$ glucose in bi-distilled water. The experimental $\gamma$ vs. $t$ data for pure oil are shown in the inserted figure.

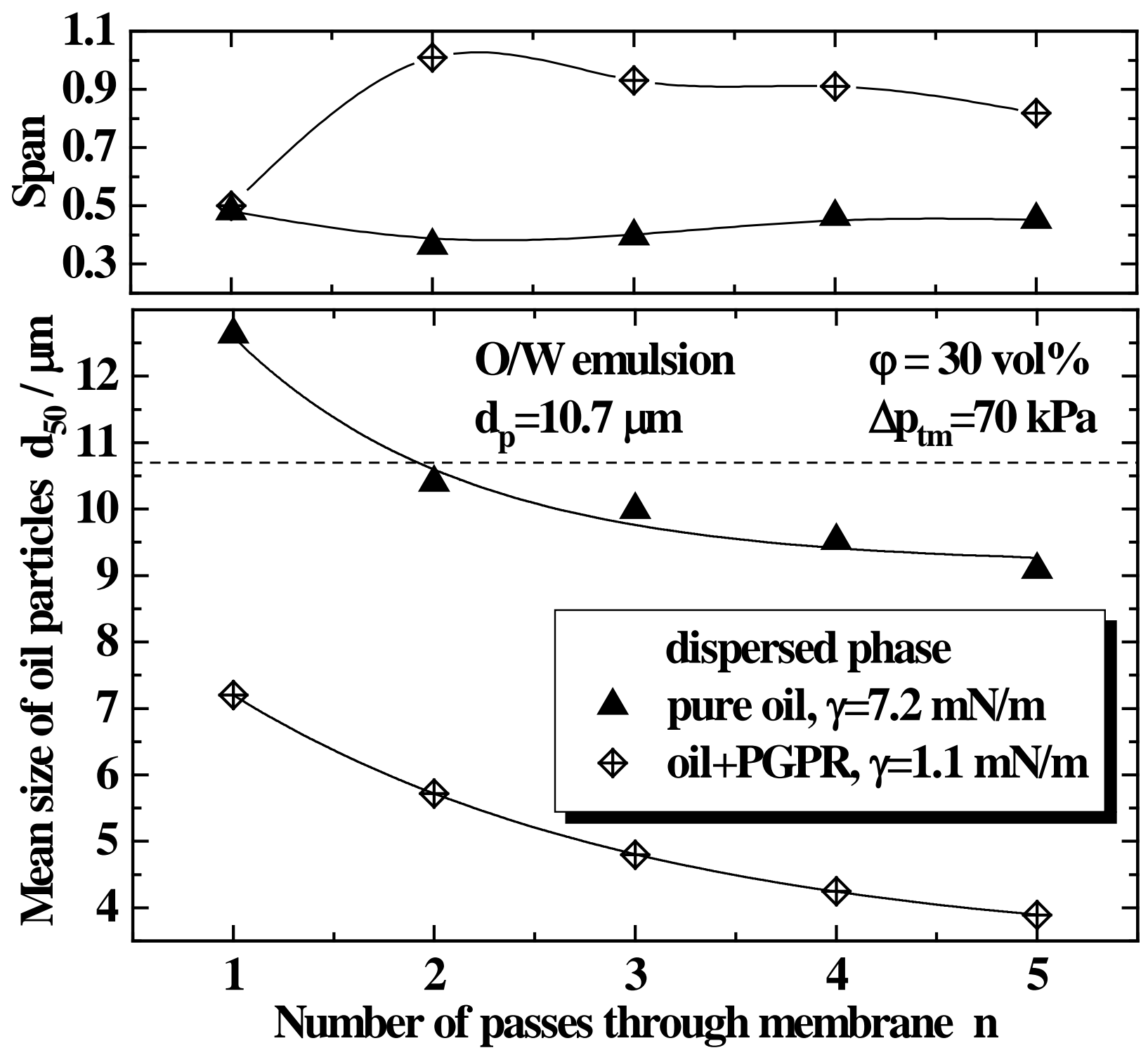


Fig. 6: The effect of the interfacial tension on the mean size and span of the particle size distribution in homogenized $\mathrm{O} / \mathrm{W}$ emulsions (continuous phase: $0.5 \mathrm{wt} \%$ Tween $80+1$ wt $\%$ Na-alginate +5 wt $\%$ glucose; dispersed phase: pure soybean oil or $5 \mathrm{wt} \%$ PGPR in soybean oil). The mean pore size is designated by the dashed line. 


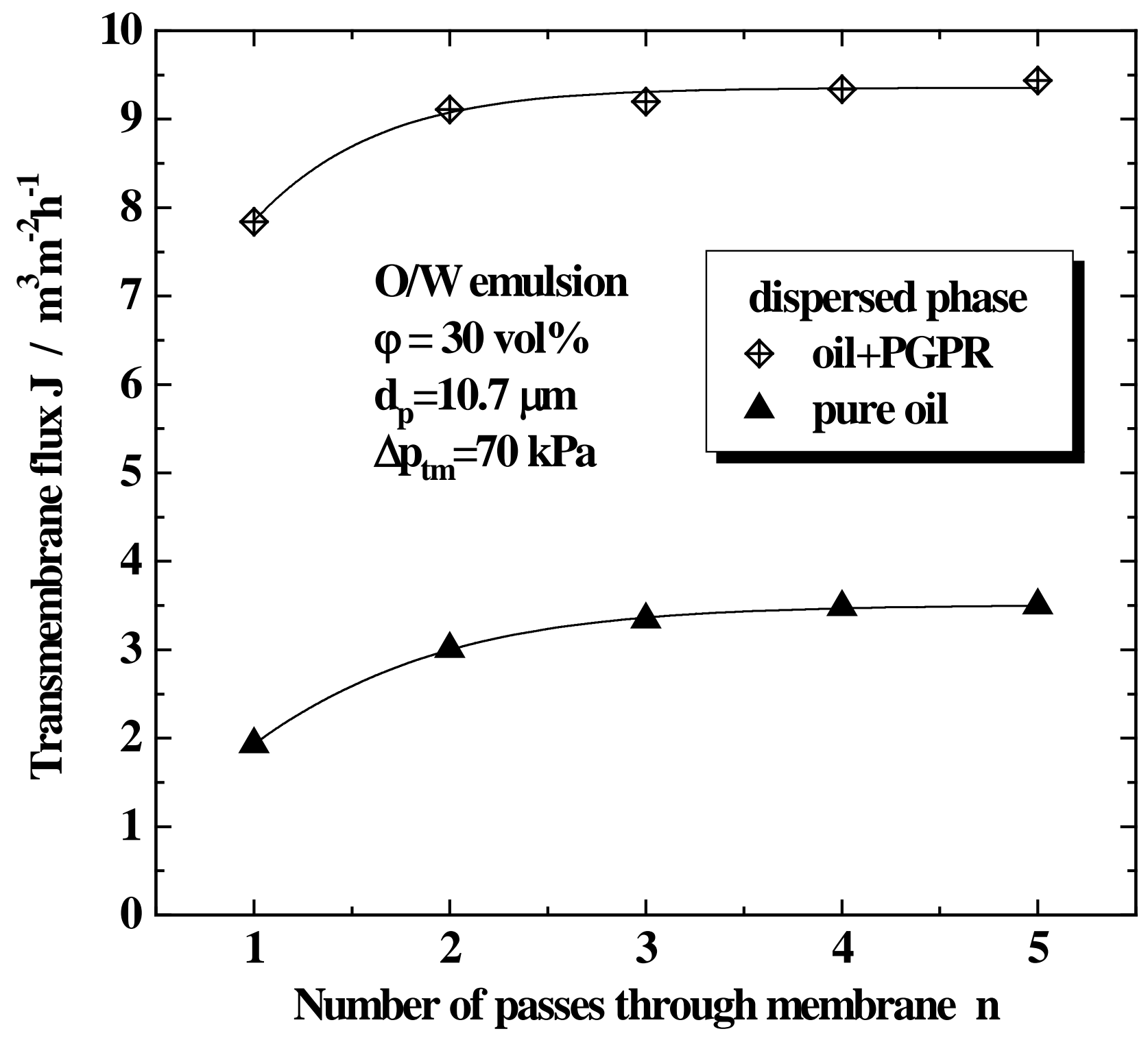

Fig. 7: The effect of the interfacial tension on the transmembrane flux (the experimental conditions as in Fig. 6). 


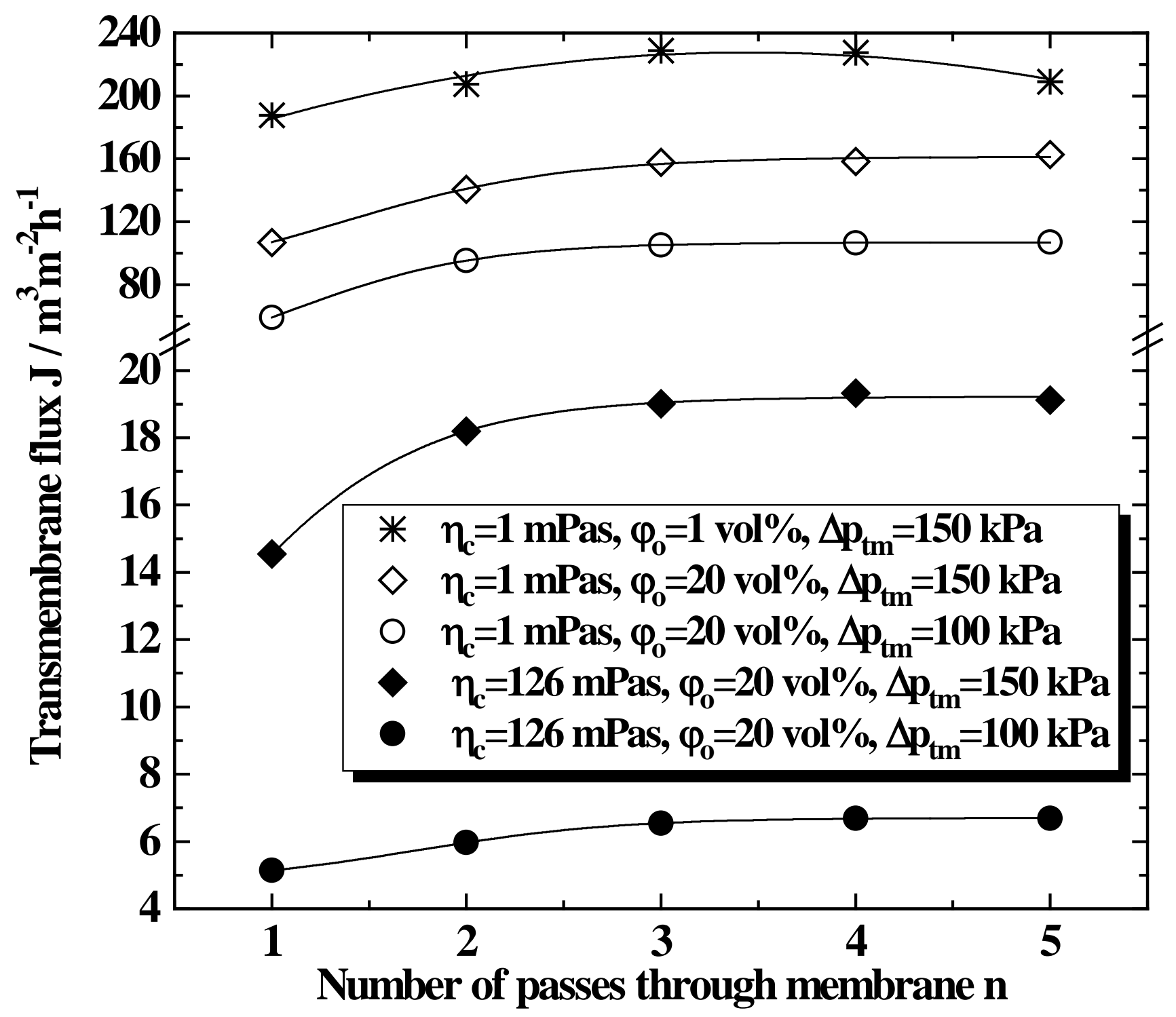

Fig. 8: The effect of the continuous phase viscosity on the transmembrane flux at two different pressures (100 and $150 \mathrm{kPa}$ ) and the contents of outer droplets ( 1 and 20 vol\%). Other conditions: $\varphi_{i}=30$ vol $\%, d_{p}=10.7 \mu \mathrm{m}$. 


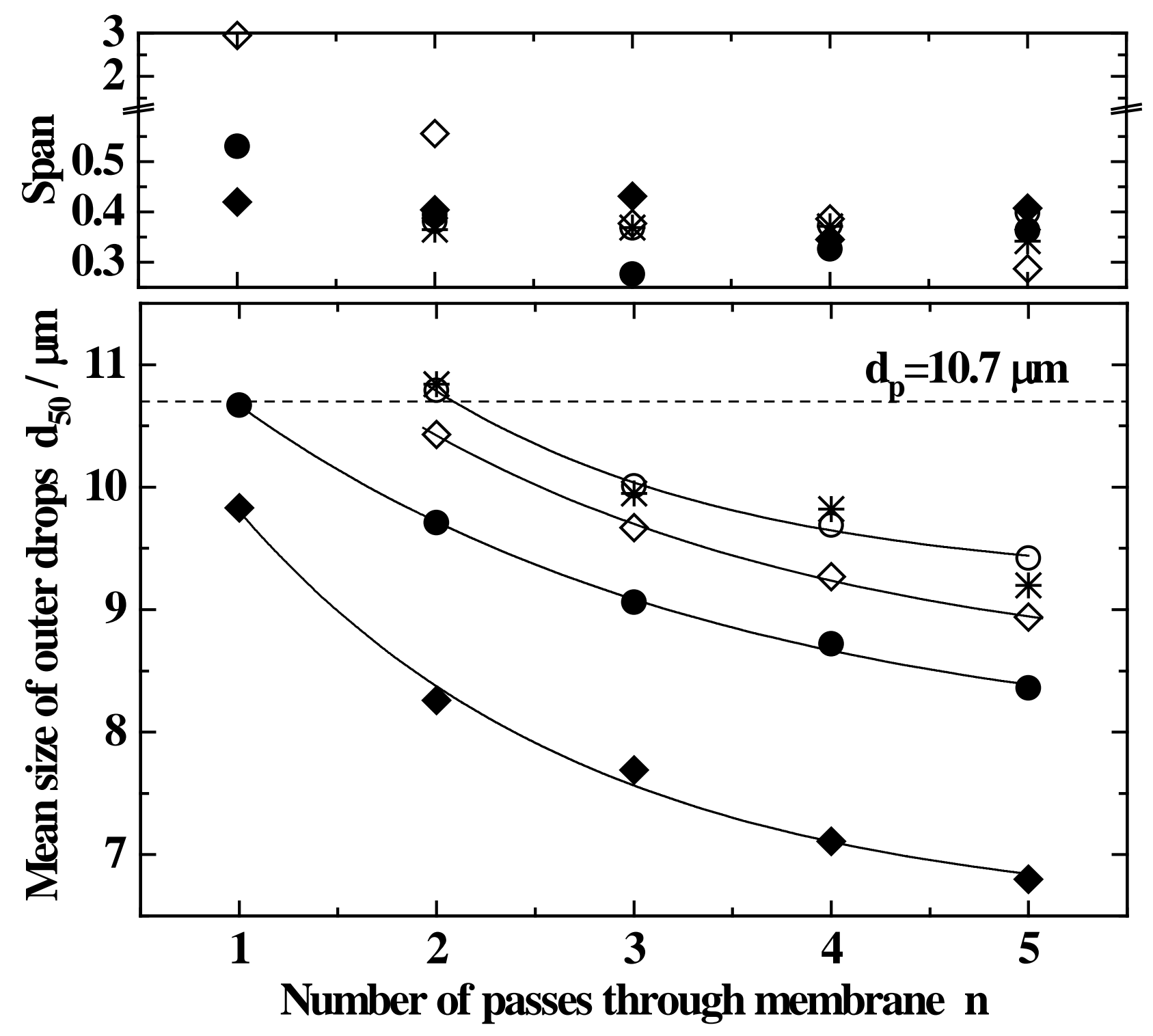

Fig. 9: The effect of the continuous phase viscosity on the mean size of outer drops. The symbols and experimental conditions are the same as in Fig. 8. 


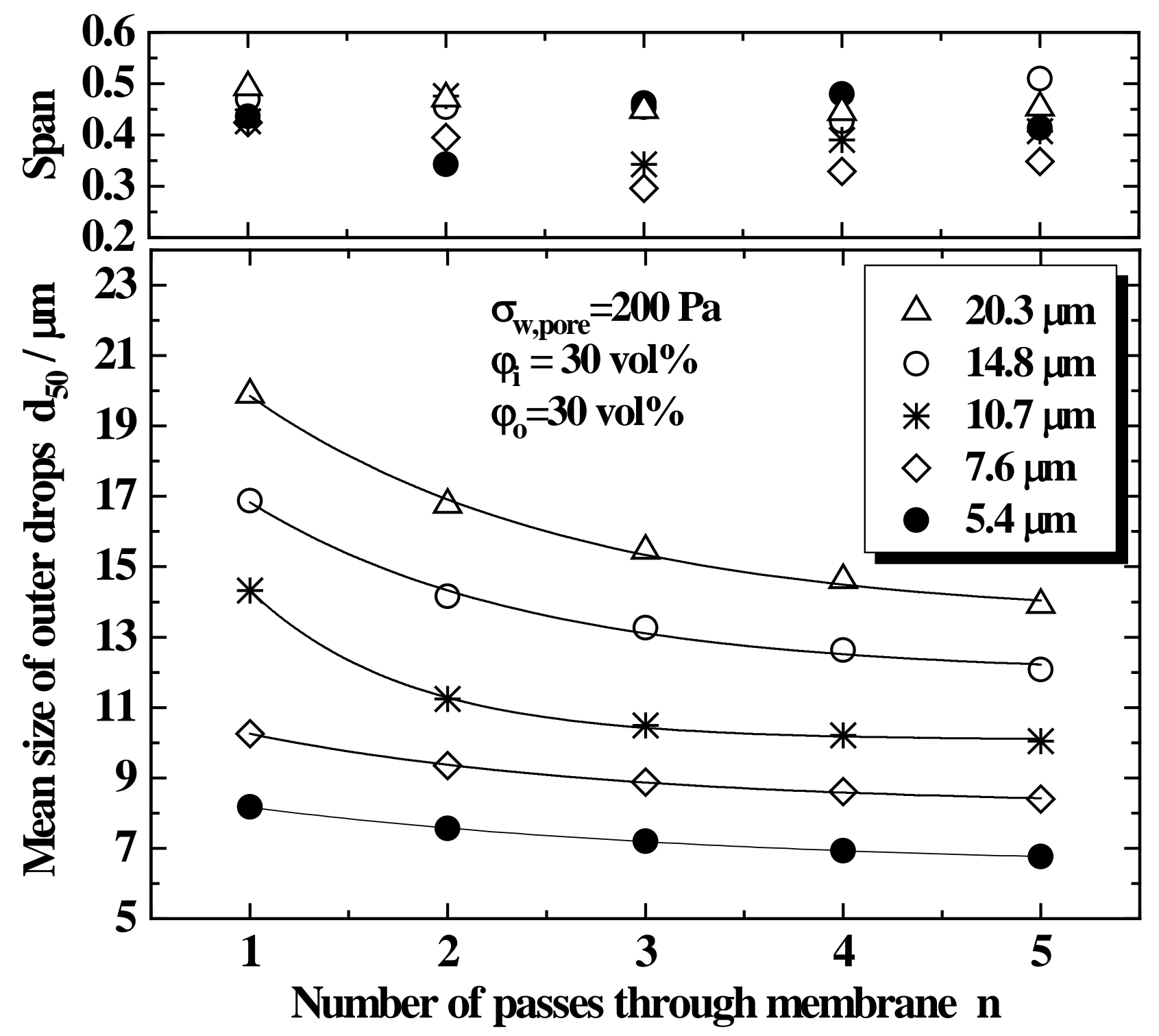

Fig. 10: The effect of the mean pore size on the mean droplet size at the constant shear stress of continuous phase inside pores of approximately $200 \mathrm{~Pa}\left(\eta_{\mathrm{c}}=126\right.$ mPas). 


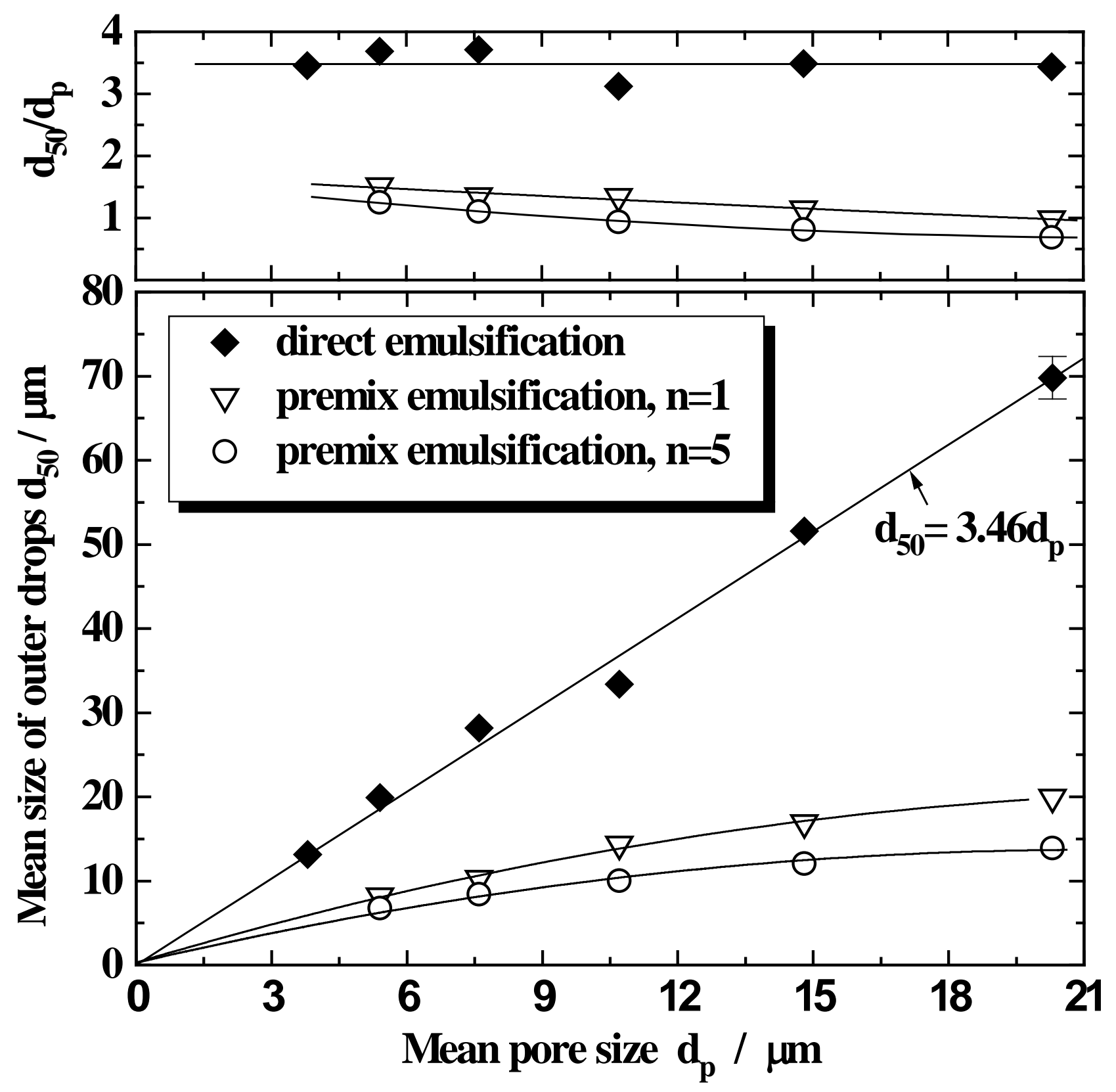

Fig. 11: The relationship between the mean droplet size and the mean pore size for multiple emulsions prepared using direct stirring membrane emulsification (stirring rate $=400 \mathrm{rpm})$ and repeated premix emulsification $\left(\sigma_{\mathrm{w} \text {,pore }}=200 \mathrm{~Pa}\right)$. 


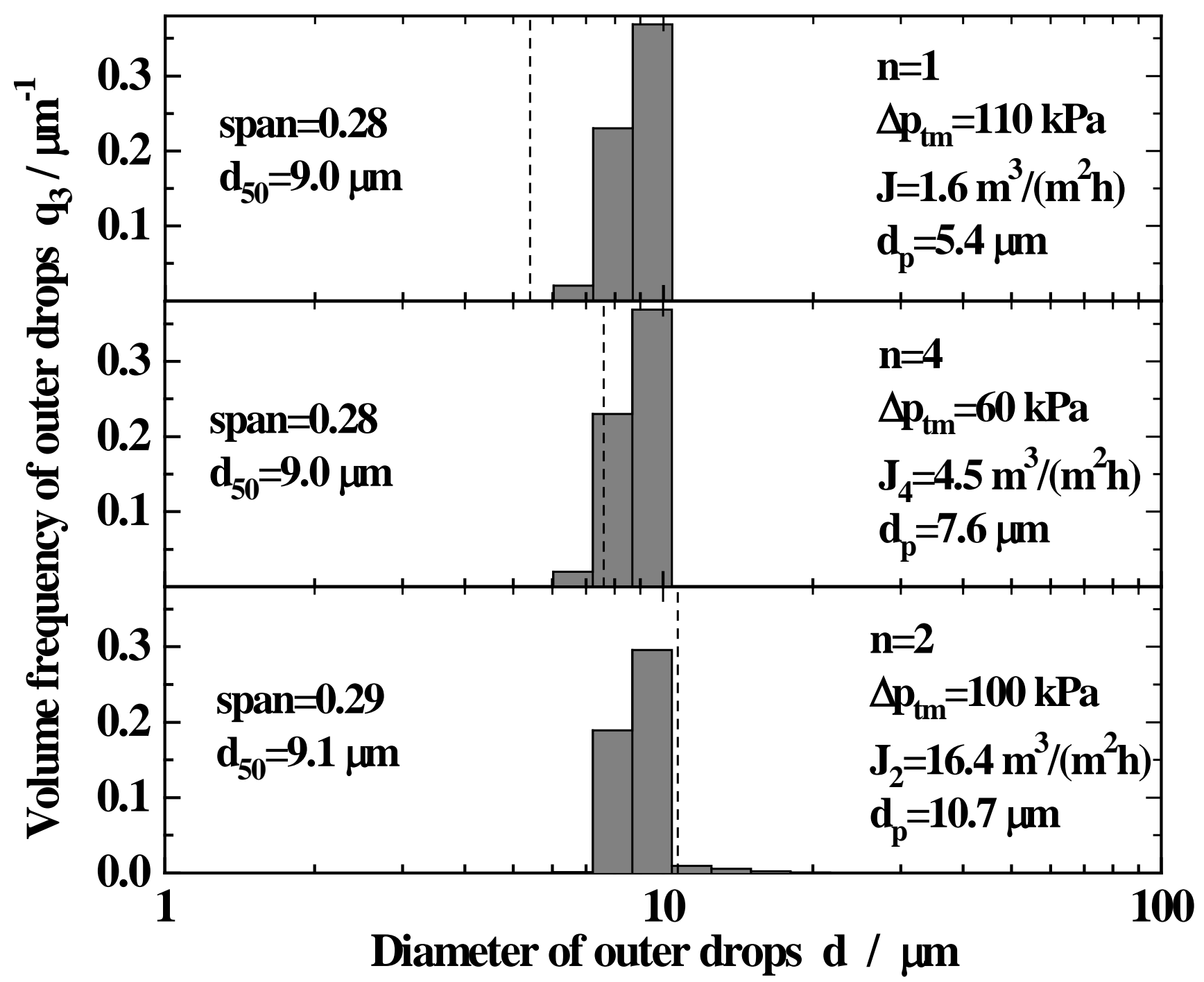

Fig. 12: The size distribution of outer drops prepared using SPG membranes with different mean pore sizes under such conditions to obtain almost the same 
particle size distribution. The dashed line represents the mean pore size $\left(\varphi_{0}=1\right.$ vol $\left.\%, \varphi_{\mathrm{i}}=30 \mathrm{vol} \%, \eta_{\mathrm{c}}=126 \mathrm{mPas}\right)$. 
(A) Direct method, $d_{p}=10.7 \mu \mathrm{m}$

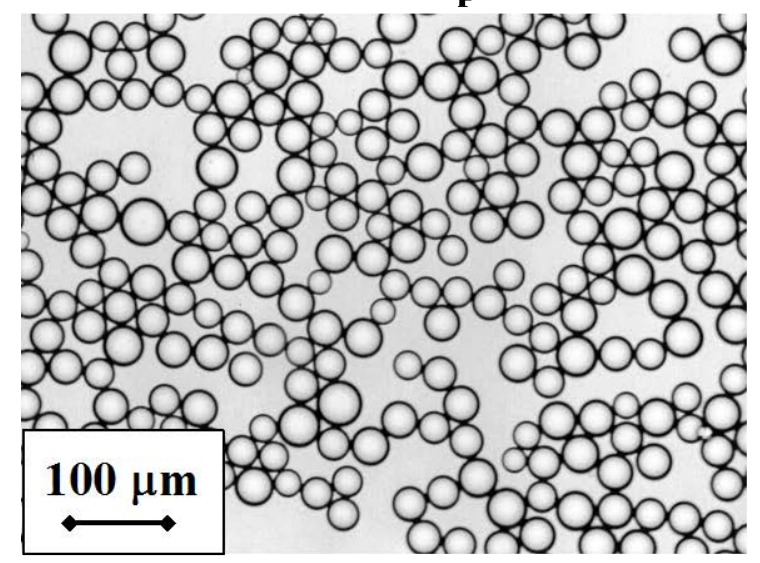

$\mathrm{d}_{50}=32 \mu \mathrm{m}, \mathrm{span}=0.32$

(C) Direct method, $d_{p}=5.4 \mu \mathrm{m}$

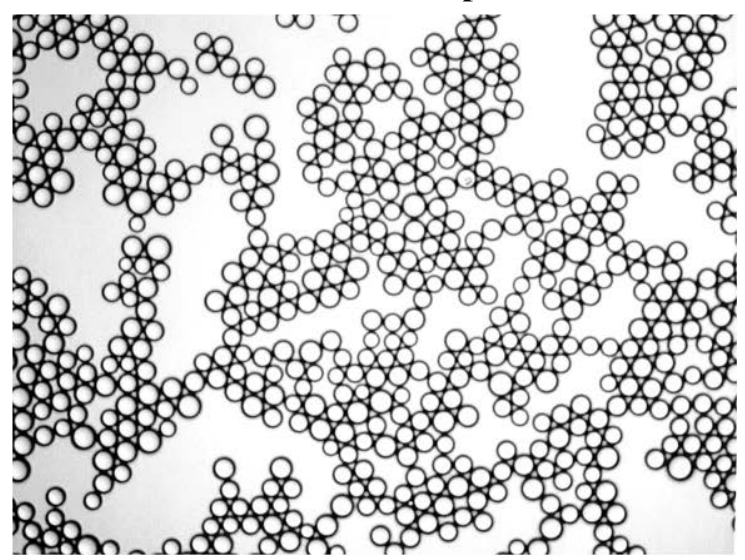

$d_{50}=19.5 \mu \mathrm{m}, \mathrm{span}=0.31$
(B) Direct method, $d_{p}=7.6 \mu \mathrm{m}$

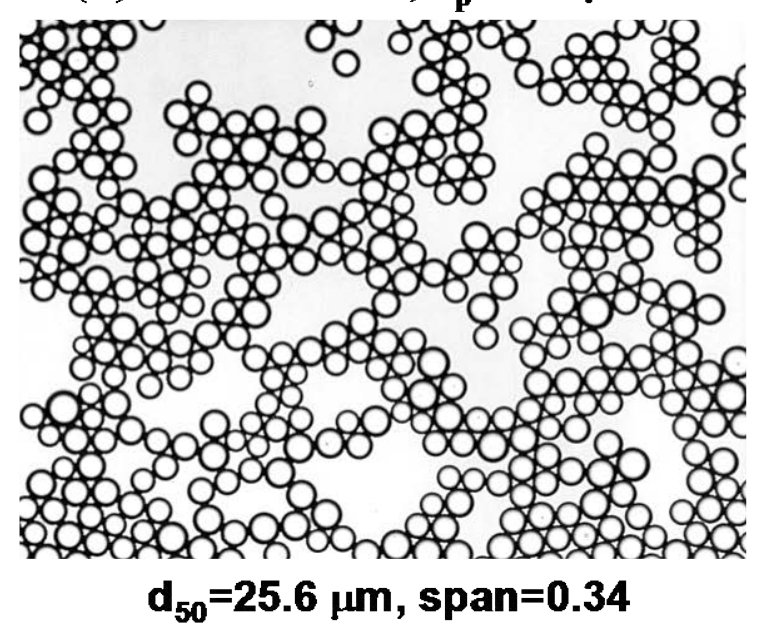

(D) Premix method, $d_{p}=5.4-10.7 \mu \mathrm{m}$

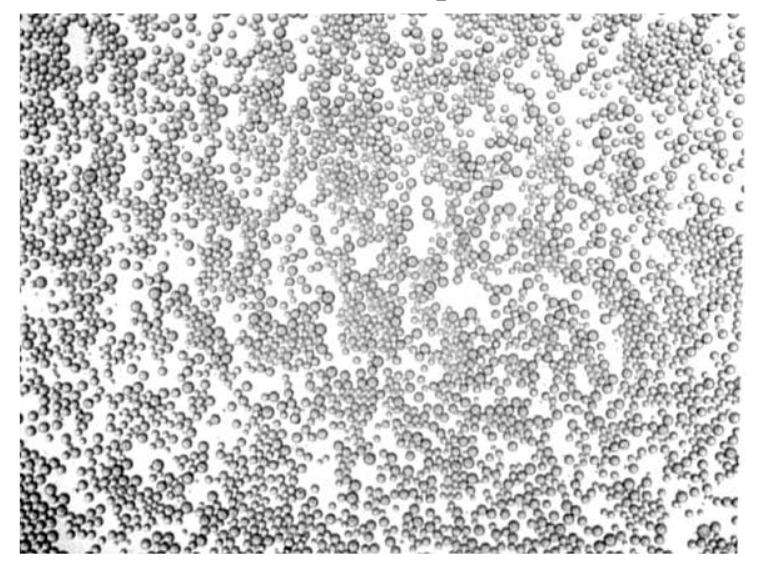

$\mathrm{d}_{50}=9 \mu \mathrm{m}, \operatorname{span}=0.28$

Fig. 13: The micrographs of droplets produced by direct and repeated premix emulsification using SPG membrane with a pore size of 5.4, 7.6, and $10.7 \mu \mathrm{m}$. In the case of premix emulsification (D), the emulsions with the same particle size distribution can be produced, as shown in Fig. 12. 


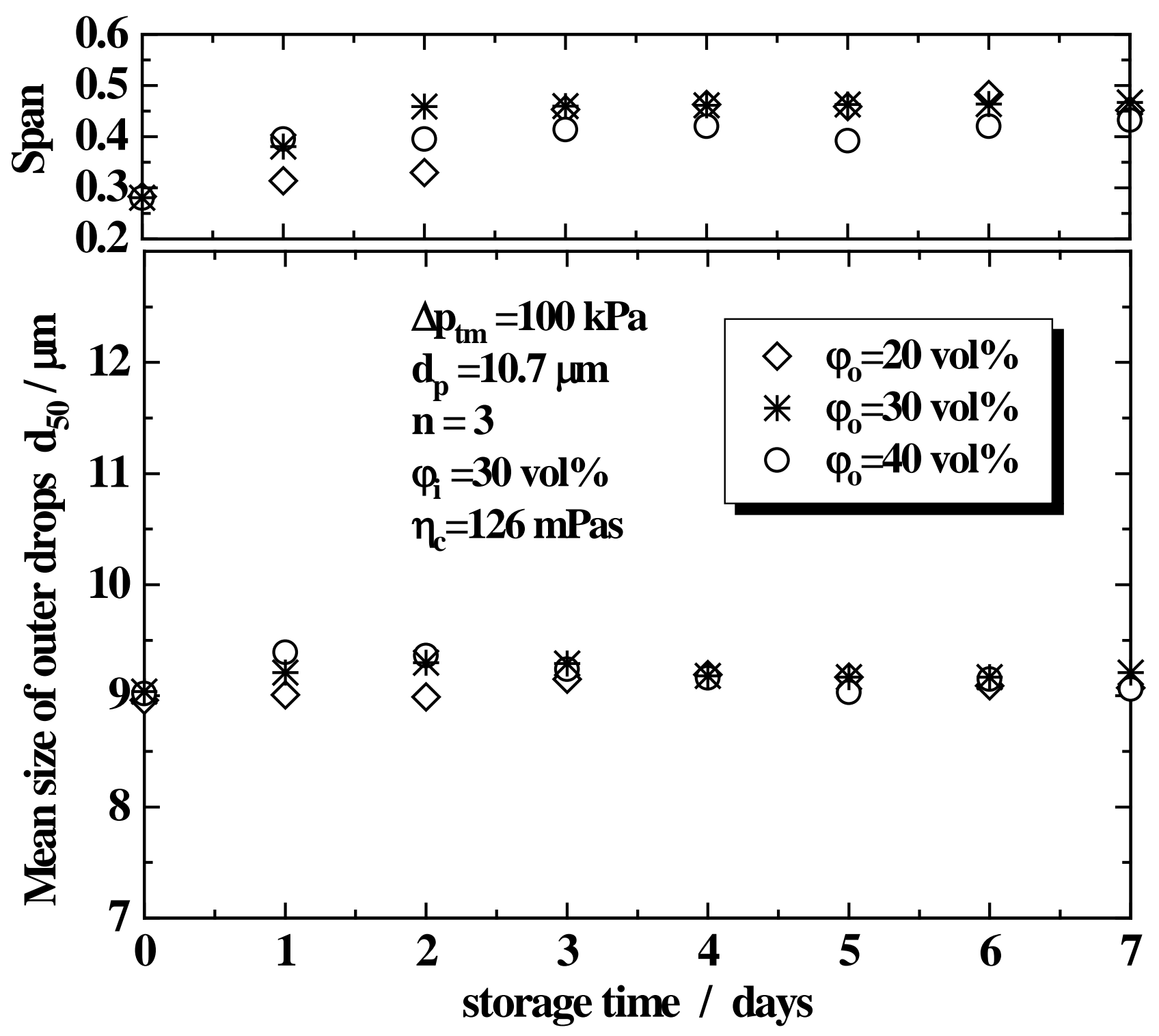

Fig. 14: The variation of the mean particle size and the span of particle size distribution of outer droplets during storage of multiple emulsions with different dispersed phase contents for one week at room temperature. 